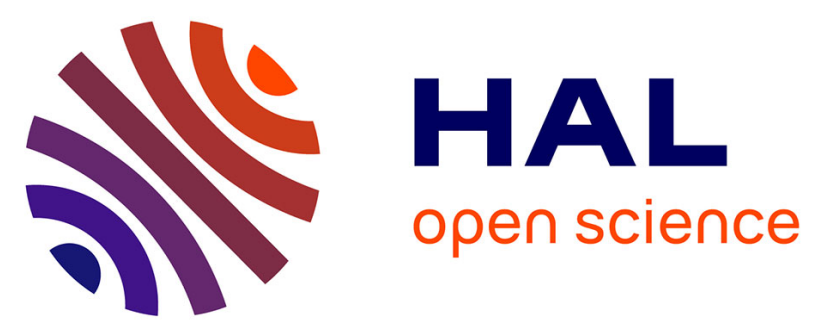

\title{
Incoherent broad-band cavity enhanced absorption spectroscopy for sensitive and rapid molecular iodine detection in the presence of aerosols and water vapour
} Chiheb Bahrini, Anne-Cécile Grégoire, Dorel Obada, Christian Mun, Christa Fittschen

\section{To cite this version:}

Chiheb Bahrini, Anne-Cécile Grégoire, Dorel Obada, Christian Mun, Christa Fittschen. Incoherent broad-band cavity enhanced absorption spectroscopy for sensitive and rapid molecular iodine detection in the presence of aerosols and water vapour. Optics and Laser Technology, 2018, 108, pp.466-479. 10.1016/j.optlastec.2018.06.050 . hal-02322045

\section{HAL Id: hal-02322045 \\ https://hal.science/hal-02322045}

Submitted on 16 Jul 2020

HAL is a multi-disciplinary open access archive for the deposit and dissemination of scientific research documents, whether they are published or not. The documents may come from teaching and research institutions in France or abroad, or from public or private research centers.
L'archive ouverte pluridisciplinaire HAL, est destinée au dépôt et à la diffusion de documents scientifiques de niveau recherche, publiés ou non, émanant des établissements d'enseignement et de recherche français ou étrangers, des laboratoires publics ou privés.

\section{(ㅇ)(1) $\$$}

Distributed under a Creative Commons Attribution - NonCommercial - NoDerivatives 44.0 


\title{
Incoherent Broad-Band Cavity Enhanced Absorption Spectroscopy for sensitive and rapid molecular iodine detection in the presence of aerosols and water vapour
}

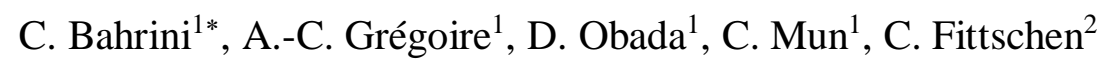

${ }^{1}$ Institut de Radioprotection et de Sûreté Nucléaire (IRSN), PSN-RES, Cadarache, Saint Paul lez Durance, 13115, France

${ }^{2}$ Univ. Lille 1, CNRS, UMR 8522 - PC2A - Physicochimie des Processus de combustion et de l'atmosphère, F-59000 Lille, France.

* Corresponding author: chiheb.bahrini@ipeit.rnu.tn

\begin{abstract}
The atmospheric chemistry of iodine is important in different environments, and particularly in case of a nuclear reactor severe accident. This paper describes the performance of an Incoherent Broad-Band Cavity Enhanced Absorption Spectroscopy (IBB-CEAS) device, based on a green LED source allowing the online detection of gaseous molecular iodine. High sensitivities and a wide dynamic range are obtained. The performances and limitations of the IBB-CEAS technique for measurements of iodine in the presence of aerosols and water vapour are discussed. The capabilities of this device to perform kinetics studies on iodine have been investigated in the framework of nuclear reactor accident research. The re-vaporization process of deposited CsI by optical monitoring of $\mathrm{I}_{2}$ concentration-time profiles is presented. The aerosols used in the experiments have been well characterized (size, distribution, concentration and mass) before interaction with iodine by a NanoScan scanning mobility particle sizer (SMPS), a PEGASOR particle sensor PPS-M and a tapered element oscillating microbalance (TEOM).
\end{abstract}

Keywords: Sensors; Optical resonators; Absorption Spectroscopy; Light-emitting diodes (LEDs).

\section{Introduction}

During a nuclear power plant severe accident ${ }^{(1)}$, radionuclides of iodine constitute one of the main concerns of post-accident management because of their high radiotoxicity induced by their affinity for the thyroid. Indeed, in the case of a nuclear power reactor core melt accident, the volatile fission products (iodine, caesium and molybdenum) can almost completely released 
from the degraded fuel and transported through the reactor coolant system into the reactor containment building.

If core degradation cannot be stopped through cooling, the accident may ultimately lead to loss of containment integrity and large releases of radioactivity into the environment. The Fukushima-Daiichi accident in 2011 showed that external hazards (in this case, a tsunami triggered by an earthquake) with a magnitude greater than a facility's design basis could also lead to core meltdowns. This accident resulted in significant amounts of radioactivity being released into the environment ${ }^{(2)}$.

The radioactive aerosols and gaseous iodine emitted into the atmosphere may interact with each other in the short term or with atmospheric aerosols. Thus, the interactions between iodine in the gas phase and aerosols should be considered and need to be studied.

Over the past two decades, the French Institute for Radioprotection and Nuclear Safety (IRSN) has invested large resources on Severe Accident research. The overall aim of this work is to predict better the potential releases of fission products into the containment atmosphere and finally into the environment, with emphasis on iodine species.

However several issues remain to be addressed. With this in mind, to complete and better understand the volatile iodine formation, deposition and decomposition, several laboratory scale experiments have been performed at IRSN to examine the behaviour of iodine with aerosols transported in the Reactor Cooling System (CHIP-program Chimie de l'Iode dans le Circuit Primaire ${ }^{(3)}$ ) and in the reactor containment building (EPICUR program Experimental Program of Iodine Chemistry Under Radiation ${ }^{(1)}$ ). The Source Term Evaluation and Mitigation STEM/EPICUR tests (performed under the aegis of OECD/NEA/CSNI) were dedicated to study the release under radiation of iodine species deposited onto painted surfaces in the containment atmosphere. Further researches have been carried out within the framework of the French MIRE program ${ }^{(4)}$ (Mitigation of Releases to the Environment in the event of a nuclear accident) in the strategy to investigate and to improve the mitigation of radioactive releases after a core melt accident. The second phase of the project named Source Term Evaluation and Mitigation 2 (STEM 2), coordinated by IRSN, will be focused on mid- and long-term iodine releases ${ }^{(3)}$.

These experiments aimed at simulating the conditions of a severe nuclear accident at high temperature $\left(100\right.$ to $1600{ }^{\circ} \mathrm{C}$ ): the presence of aerosols (up to several $\mathrm{mg} / \mathrm{m}^{3}$ ), carrier gas including air, hydrogen or water vapour (from $0 \%$ up to $100 \%$ ) and a high dose rate in particular cases. 
One of the main goals is to be able to determine the fraction of gaseous iodine (mainly $\mathrm{I}_{2}$ ) at trace levels ( ppbv) with a sufficiently high time resolution to allow kinetics studies.

It should be recalled that the experimental conditions for such studies are rather different from atmospheric conditions: i) in the atmosphere, the water vapour distribution is highly variable spatially and temporarily. Water vapour varies from a trace to a few \% (by volume). On the contrary, the amount of water vapour considered in this work is well above atmospheric levels (can be up to 100\%). ii) the amount of aerosols and iodine released in severe accident scenarios. The mass of aerosols (fission products, heavy nuclei, materials of the structures and control rods) released into the containment during fuel degradation may be high (i.e., around $1500 \mathrm{~kg}$ for a 900 MWe Pressurized Water Reactor (PWR) ${ }^{(1)}$. Following an accident with release into the atmosphere, these aerosols may agglomerate and settle. This results in a reduction for the aerosol mass suspended in the containment atmosphere by a factor of 2500 (48 hours after the last releases). The $900 \mathrm{MWe}$ reactor containment has a total volume of $\approx 60 \times 10^{3} \mathrm{~m}^{3}$ giving a mass density of aerosols of about $10 \mathrm{mg} / \mathrm{m}^{3}$.

The use of ${ }^{131}$ I to label iodine allows continuous $\gamma$-measurements in order to follow on-line the release of the gaseous iodine. Gamma-spectrometry features high sensitivity and a suitably short time resolution $(\sim \min )$ to follow the kinetics of the studied reaction ${ }^{(1,5)}$. However, the use of radiotracers induces high costs, safety procedures and regulatory issues. When the use of radiotracers is not possible (high temperature studies, needs for stable iodine generation for several hours), more conventional systems have to be considered such as quartz aerosol filters followed by gas scrubbers filled with a sodium hydroxide solution $(1 \mathrm{M})$ in order to trap the gaseous iodine species. Besides the low time resolution of such system (at best $\sim 30 \mathrm{~min}$ ) the first tests in the CHIP line showed strong adsorption of gaseous iodine onto aerosols trapped on the inlet filter device, thus hindering accurate detection of low gaseous iodine concentrations. This system was then successfully replaced by a direct scrubbing of the transported flow (containing both the aerosols and gaseous iodine) into an organic phase in which only $I_{2}$ is retained ${ }^{(6)}$. It is the low time resolution (connected to the low sensitivity) which makes the previous technique mentioned inappropriate for the tests. Nevertheless, due to its low sensitivity (accumulation 30 to $60 \mathrm{~min}$ ), this system is not suited for kinetic studies. For this purpose, O. Johansson et al. ${ }^{(7)}$ developed recently an on-line optical instrument based on an Incoherent Broad-Band Cavity Enhanced Absorption Spectroscopy IBB-CEAS and operating in the green spectral range $500-550 \mathrm{~nm}$.

There are a few existing optical spectroscopy and mass spectrometry methods for molecular iodine measurements ${ }^{(8)}$, such as Long-Path Differential Optical Absorption Spectroscopy (LP- 
DOAS) ${ }^{(9-12)}$, Laser Induced Fluorescence (LIF) ${ }^{(13-15)}$, denuder sampling followed by Inductively Coupled Plasma Mass Spectrometry (ICP/MS) ${ }^{(10,16-18)}$, chemical ionization mass spectrometry ${ }^{(19)}$ and cavity enhanced techniques such as Broad-Band Cavity Ring Down Spectroscopy (BB-CRDS) and Cavity Ring Down Spectroscopy (CRDS) ${ }^{(10,20,21)}$. All have good sensitivity, with reported detection limits being on the order of $\sim 5 \mathrm{pptv}$ (30 min acquisition time) for LP-DOAS ${ }^{(9)}, 20$ pptv (10 minute acquisition time) for BB-CRDS ${ }^{(20)}, 13$ pptv for LIF (10 min integration time) ${ }^{(15)}$ and $\sim 26$ pptv (1 min acquisition time) for IBB-CEAS ${ }^{(22)}$. The quoted detection limits will of course change depending on the presence and concentration of other species that absorb at the same wavelength as $I_{2}$.

LP-DOAS can be immediately disregarded for laboratory measurements, as it requires a single pass path length of tens of metres to kilometres. LIF is a very sensitive technique (a detection limit of $\sim 2 \times 10^{9}$ molecule $\mathrm{cm}^{-3}$ is reported in ${ }^{(13)}$ ) but it does not provide absolute measurements and therefore it requires calibration.

In order to achieve absolute measurements with a good sensitivity while retaining a compact device, a cavity enhanced technique is required. Of these there are two main techniques of interest: Broad-Band Cavity Ring Down Spectroscopy (BB-CRDS) and Incoherent Broad-Band Cavity Enhanced Absorption Spectroscopy (IBB-CEAS) ${ }^{(23)}$.

CRDS data retrieval becomes more complicated when the spectral width of the incoming light is comparable to or broader than that of the absorption line of the species in question. The ringdown decay is no longer single-exponential, but becomes multi-exponential ${ }^{(24)}$. However, cavity ring-down techniques have some advantages, namely that it is not necessary to know the reflectivity of the mirrors, and the intensity fluctuations of the incoming radiation are not important, as it is the decay time that is being measured. By contrast, IBB-CEAS is more analogous to standard absorption experiments. There are multiple advantages of IBB-CEAS compared to other techniques: by virtue of the cavity enhanced nature of the technique, IBBCEAS gains in terms of sensitivity, size and stability compared to both simple absorption and long path absorption techniques. This enables spectra to be taken at short integration times (depending on concentration and other interferences, seconds to minutes). The experimental design is simple compared to more complicated techniques that require fast electronics or sophisticated optics such as mode-locking, feed-back loops, optical isolators, Faraday switches, frequency comb spectroscopy. The use of broad band light sources such as xenon arc lamp ${ }^{(22,25,26)}$, supercontinuum sources ${ }^{(27,28)}$ and light emitting diodes (LEDs) ${ }^{(29-30)}$ for probing spectral light allows simultaneous quantitative assessment of multiple atmospheric species ${ }^{(30)}$. 
The use of a LED light source is a very low cost solution, and by changing the LED and the mirrors, other wavelength ranges can easily be investigated from the ultraviolet (UV) to the visible, allowing access to the spectral regions that involve strong fundamental electronic transitions of gaseous molecules. This is also of importance when a measurement of one species in the presence of an unknown concentration of a secondary broad absorber is required, as will be seen later. Finally, no optical mode matching is involved as in some Cavity Ring Down Spectroscopy applications (CRDS), which makes IBB-CEAS apparatus much simpler, more stable and robust. There are two main drawbacks however; unlike CRDS, the sensitivity is dependent on the light source stability and the measurement accuracy of the transmitted intensity and it requires a reliable calibration procedure to determine baseline optical losses of the system (often performed by calibration of reflectivity as a function of wavelength using a sample of known concentration in the cavity). This can be calibrated by introducing a known concentration of an absorbing species into the cell. IBB-CEAS has been successfully used to measure a number of atmospheric trace gas compounds like $\mathrm{I}_{2}{ }^{(7,22,29)}, \mathrm{IO}^{(22,38)}$, OIO ${ }^{(22)}, \mathrm{NO}_{2}$ ${ }^{(29,31,32,38-41)}, \mathrm{NO}_{3}{ }^{(29,31,40,42)}, \mathrm{O}_{2}{ }^{(27,29,34,40)}, \mathrm{C}_{2} \mathrm{H}_{2}{ }^{(27)}, \mathrm{CO}_{2}{ }^{(28)}, \mathrm{CH}_{4}{ }^{(28)}, \mathrm{H}_{2} \mathrm{O}^{(29,32,38,40,41)}, \mathrm{HONO}$ ${ }^{(30)}, \mathrm{CHOCHO}^{(32,38,39,41)}, \mathrm{CH}_{3} \mathrm{COCHO}^{(38,39)}, \mathrm{CH}_{2} \mathrm{O}^{(33,37)}, \mathrm{O}_{3}{ }^{(35,36)}, \mathrm{O}_{4}{ }^{(38,40,41)}, \mathrm{N}_{2} \mathrm{O}_{5}{ }^{(42)}, \mathrm{Br}_{2}{ }^{(36)}$, $\mathrm{BrO}^{(36)}, \mathrm{SO}_{2}{ }^{(36)}, \mathrm{OClO}^{(37)}$.

A few Cavity Enhanced Absorption Spectroscopy (CEAS) setups based on the coupling of a laser source to a high finesse cavity have been reported in the literature for our region of interest. High-sensitivity Broad band Cavity Ring Down Spectroscopy (BB-CRDS) based on pulsed dye laser pumped by Nd:YAG laser (at a $20 \mathrm{~Hz}$ repetition rate) emitting in the green part of the spectrum at around $568 \mathrm{~nm}$, have already demonstrated 20 ppt $\mathrm{I}_{2}$ and 4 ppt OIO sensitivity in an integration time of $10 \mathrm{~min}^{(20)}$. Unlike a conventional CRDS ${ }^{(24)}$, the dispersion grating was removed from the dye laser cavity which allowed the entire broadband light output of the oscillator stage to be amplified.

S. M. Ball et al. extended broadband CEAS techniques to the use of light emitting diodes (LEDs) ${ }^{(29)}$. The broadband CEAS spectrum of molecular iodine has been recorded in the spectral range $521-571 \mathrm{~nm}$ at a resolution of $\sim 0.09 \mathrm{~nm}$ using green LED coupled into a $1.5 \mathrm{~m}$ cavity. A detection limit of 991 pptv (exposure time $300 \mathrm{~s}$ ) for $I_{2}$ has also been retrieved from broad band CEAS spectra using spectral fitting techniques adapted from differential optical absorption spectroscopy. 
This work describes the evolutions and improvements of the IBB-CEAS instrument recently developed by O. Johansson et al. ${ }^{(7)}$ and its abilities to work under different experimental conditions. The stability and time resolution as well as the measurable iodine concentration range is discussed (section III). The performance of the instrument in presence of steam (up to $\sim 80 \%$ ) and aerosols (inorganic aerosols of size range (nm to $\mu \mathrm{m})$ ) is tested (section IV, V). Finally a successful application of this instrument is reported (section VI).

\section{Experimental Section: Material and Methods}

\section{IBB-CEAS device}

\subsection{IBB-CEAS theory and DOAS principle}

The IBB-CEAS method is based on the measurements of light transmitted through a highfinesse optical cavity ${ }^{(34)}$. Since the mirror reflectivity $R$ is usually very close to 1 in most IBBCEAS applications, the optical extinction coefficient $\alpha(\lambda)$ due to sample present inside the

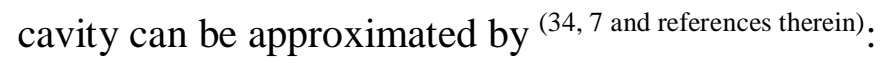

$$
\alpha(\lambda) \approx \frac{1-R(\lambda)}{d}\left(\frac{I_{0}(\lambda)}{I(\lambda)}-1\right)
$$

In order to determine the absorbance directly from equation (1) we need the cavity mirror reflectivity spectrum $R(\lambda)$ and the effective path length $d$. The mirror reflectivity could be determined from the known Rayleigh scattering of $\mathrm{He}$ and zero air as described in Washenfelder et al. ${ }^{(32,33)}$. A more reliable alternative is calibrating concentration measurements using a reference spectrum from a sample of known concentration ${ }^{(7,31)}$. Using this calibration method does not require any reference absorption cross-section which is convenient in our case since the iodine absorption cross-sections are unknown at $100{ }^{\circ} \mathrm{C}$. Therefore the data that can be retrieved from the IBB-CEAS analysis is the measure of the ratio of the sampling and calibration iodine density $N_{\text {rel }}=n_{\mathrm{I}_{2}, \text { sampling }} / n_{\mathrm{I}_{2}, \text { calib }}$.

Aerosols often perturb measurements and need to be removed from the cavity by means of filtration in sampling lines to enable quantitative measurements. However the use of filters might cause heterogeneous losses and chemical interference on the filter surfaces which could affect the measurements.

Aerosols extinction does not possess any fine structure and can thus be treated as unstructured background effect. In this work, the trace gas absorption was quantitatively characterized by simultaneous measurement of gas absorption and aerosol extinction by Differential Optical Absorption Spectroscopy (DOAS) approach. In DOAS, a modeled differential absorption spectrum is fitted to the experimental spectrum using a least squares method to retrieve the 
target gas concentrations ${ }^{(43)}$. The principle of DOAS is to separate slowly varying parts of the absorption spectrum from rapidly varying parts. A thorough review of DOAS along with its many applications and advantages has been given elsewhere ${ }^{(38,44-46)}$.

The trace gas concentrations are retrieved by using the following equation (2):

$$
\begin{gathered}
\frac{1-R(\lambda)}{d(\lambda)}\left(\frac{I_{0}(\lambda)-B g(\lambda)}{I(\lambda)-B g(\lambda)}-1\right)=\left[\sum_{i} n_{i} \sigma_{i}(\lambda)+\sum_{j} n_{j} \sigma_{b, j}(\lambda)+\varepsilon_{\text {Ray }}(\lambda)+\varepsilon_{\text {Mie }}(\lambda)\right] \\
\frac{I_{0}-B g}{I-B g}-1=\underbrace{\frac{d}{1-R}\left[\sum_{i} n_{i} \sigma_{i}\right]}_{I_{2} \text { Rapid part }}+\underbrace{\frac{d}{1-R}\left[\sum_{j} n_{j} \sigma_{b,}+\varepsilon_{\text {Ray }}+\varepsilon_{\text {Mie }}\right]}_{\text {Broadband Slow part }} \\
\frac{I_{0}-B g}{I-B g}-1=\frac{d}{1-R} n_{I_{2}} \sigma_{I_{2}}+\underbrace{\sum_{k=0}^{n} a_{k} \lambda^{k}}_{\text {polynomial in } \lambda}
\end{gathered}
$$

where $I_{0}$ is the intensity of light transmitted by the cavity without the target gas species, $I$ is the intensity of transmitted light recorded with sample gas, $B g$ designates the background signal recorded with the light source blocked, Background signals are subtracted from cavity transmission intensities as shown in equation (2), $n_{i}$ the number density of the species $i, \sigma_{i}$ is the corresponding differential (narrow band) portion of the absorption cross-section, $\sigma_{b, i}$ is the broadband component, $d$ is the single absorption path length, $\varepsilon_{R a y}$ is the extinction from Rayleigh scattering, $\varepsilon_{\text {Mie }}$ is the extinction from aerosols due to Mie scattering and $a_{k}\left(\mathrm{~nm}^{-k}\right)$ are the parameters of the polynomial. Typical absorption features can be separated into a rapidly varying part as a function of wavelength due to $I_{2}$ absorption and a slowly varying part due to all broadband processes (the sum of $\mathrm{I}_{2}$ continuum absorption and aerosol extinction). The smooth function could be found by fitting a polynomial of appropriate degree to the left hand side of equation (2): $\left(\frac{I_{0}-B g}{I-B g}-1\right)$. This polynomial could be subsequently subtracted, leaving only the rapidly varying part. It was found that a polynomial of order 25 is sufficient for describing the slowly varying parts of measured absorption features (polynomials of order $>14$ have proven to work well with aerosols present) and the method for the polynomial fit is LU Decomposition (Lower Upper Decomposition).

\subsection{IBB-CEAS setup}


The experimental setup and procedure were described in detail previously ${ }^{(7)}$, and only a brief summary is given here. The instrument operates in the $\sim 490-555 \mathrm{~nm}$ spectral range. The LED is coupled to the $50 \mathrm{~cm}$ cavity through a short focal length lens $(f=72 \mathrm{~mm})$. Based on a $\sim 50$ $\mathrm{cm}$ long optical cavity, effective absorption path lengths of up to 1-10 km can be achieved, which allows for significant enhancement of detection sensitivity while keeping the setup very compact. The cell consists of an optically stable cavity that is continuously excited by an incoherent light source. The cavity mirrors (Layertec ${ }^{\circledR}, 1-\mathrm{m}$ radius of curvature), have a maximum reflectivity greater than $99.99 \%$ at around $532 \mathrm{~nm}$. A lens of $175 \mathrm{~mm}$ focal length is placed closely behind the output mirror and focuses the cavity output into a CCD spectrometer (Andor iDus $®$ ) controlled by a PC through an USB connection. Temperature stabilization is applied to the LED and to the spectrograph.

The cell was flushed for several minutes before starting measurements. In order to avoid adsorption/desorption on surfaces and loss of iodine on the walls, the gas lines and the high optical finesse cavity were heated to a temperature of about $100{ }^{\circ} \mathrm{C}$.

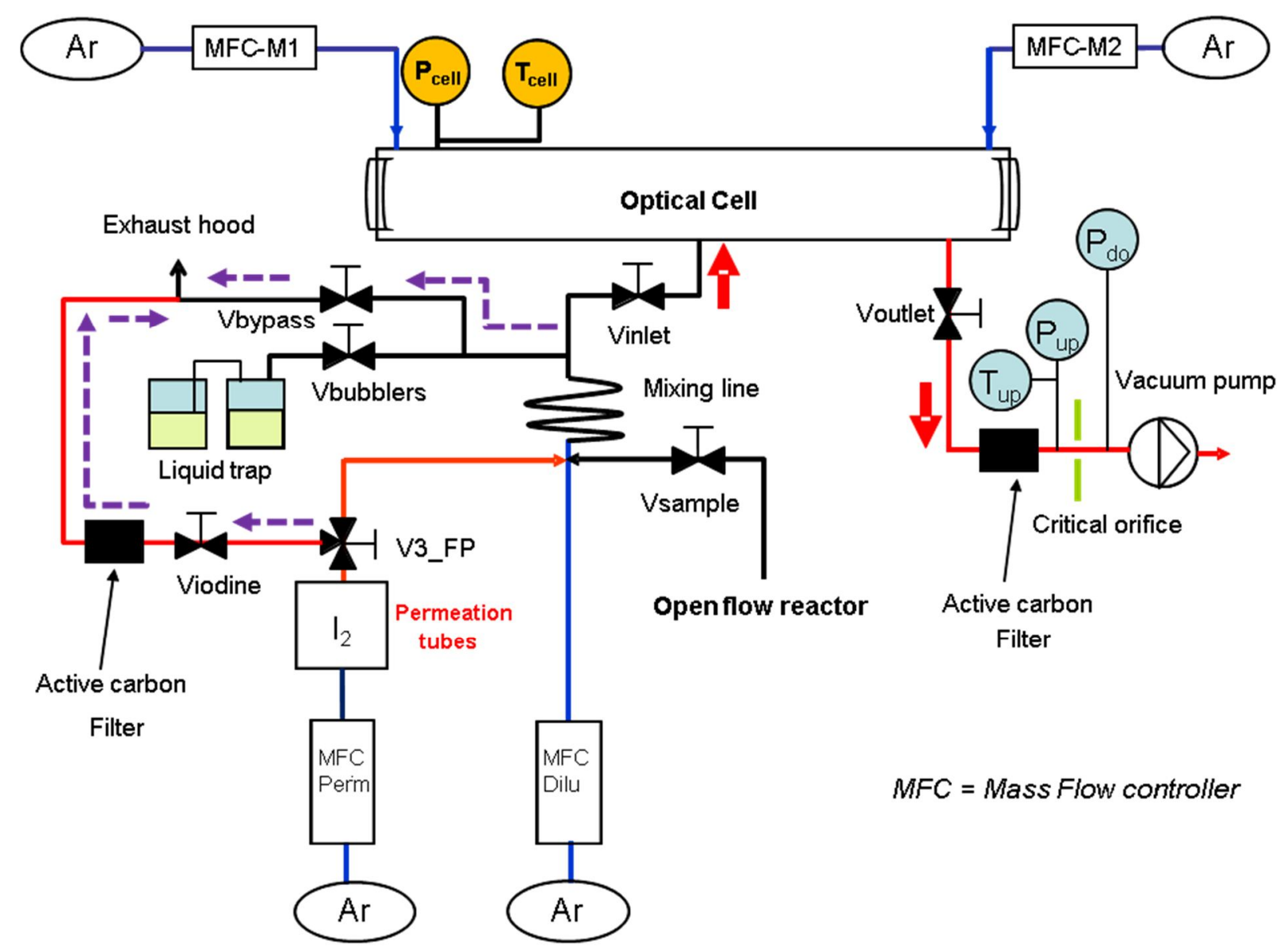

Figure. 1 Diagram of the gas lines connected to the optical cell of the IBB-CEAS device. Bypass lines are shown in Fig. 1 by purple dotted arrows. 
A general diagram of the gas lines connected to the optical cell is given in Fig. 1. The gas to be analyzed is injected into the centre of the cavity. Before the cell inlet, the gas supply system is formed by three lines which merge into a mixing line ( $2 \mathrm{~m}$ long):

- The sampling line connected to the continuous flow reactor.

- The calibration line, connected to a constant flow iodine generator. A 3-way valve allows the flow of iodine to be shifted either to the measuring cell or to the general rejection (suction hood) via a line including a manual valve and an activated carbon filter.

- A dilution line fed with argon allowing to adjust the iodine concentration injected into the cell and to ensure that the gas flow through the critical orifice is constant (see below).

The gas flow in each of these lines is controlled using a mass flow meter (Fig. 1). The fluid system contains two "bypass" lines intended to evacuate the gas excess which does not pass through the cell. For clarity, bypass lines are shown in Fig. 1 by purple dotted arrows.

- The first is located at the outlet of the permeation oven; it is used when no calibration is carried out to reject the iodine continuously generated.

- The second is positioned between the mixing line and the cell inlet allowing the excess gas flow to be discharged at the suction hood.

Finally, to reduce as much as possible the deposits and condensations of gas or aerosols on the mirrors, a protective argon flow is injected into the upper part of each mirror via two distinct lines equipped with a mass flow meter. The absorption path length $d$ is then a function of the mirror protection flow.

Note that the cell is equipped with two sensors making it possible to measure continuously the pressure and the temperature of the gas inside the cavity.

In order to have a constant flow going through the measurement cell, a critical orifice with a diameter of $560 \mu \mathrm{m}$ was inserted between the cell outlet and the vacuum pump and a bypass tube was inserted at the end of the gas mixing tube before the cell entrance. Pressure is measured upstream and downstream the critical orifice. For a $560 \mu \mathrm{m}$ critical orifice, the flow fraction taken from the cell is equal to $2.15 \mathrm{Nl} / \mathrm{min}$ (evaluated for $\mathrm{T}=20^{\circ} \mathrm{C}$ and $\Delta \mathrm{P}=\mathrm{P}_{\text {ups }}-\mathrm{P}_{\text {downs }} \sim 1$ bar).

\subsection{I $_{2}$ molar flow}

The ratio $\frac{\dot{n}_{I_{2}, \text { sampling }}}{\dot{n}_{I_{2} \text {, calib }}}$ of the molecular iodine flow at the output of the sampling line $\dot{n}_{I_{2}, \text { sampling }}$ and at the exit of the iodine generator in the calibration step $\dot{n}_{I_{2}, \text { calib }}$ can be written as: 


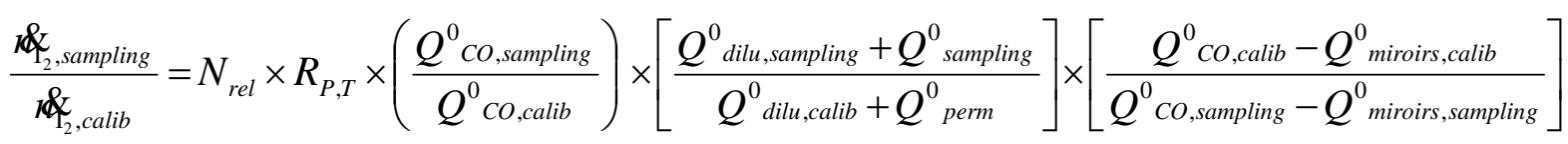

where:

- $N_{\text {rel }}=n_{\mathrm{I}_{2}, \text { sampling }} / n_{\mathrm{I}_{2}, \text { calib }}$ is the relative density of the molecular iodine in the optical cavity calculated according to the procedure described in section (1.1).

$-R_{P, T}=\left(\frac{P_{\text {cell,calib }}}{P_{\text {cell,sampling }}}\right) \times\left(\frac{T_{\text {cell,sampling }}}{T_{\text {cell,calib }}}\right)$ is the ratio of the pressures and temperatures of the fluid in the cavity during the calibration and sampling steps.

- $Q^{0}{ }_{\text {co }}, Q_{\text {dilu }}^{0}, Q_{\text {samplin }}^{0}, Q_{\text {pernand }}^{0} Q_{\text {miroir }}^{0}$ are the gas flow rates under standard conditions ( $T=0{ }^{\circ} \mathrm{C}$ and $P=1.0132$ bar) respectively through the critical orifice, injected via the dilution line, at the outlet of the sampling line, injected via the calibration line and protection of the mirrors (= sum of the flow rates at each mirror).

For constant mirror protection flows and in situations where the pressure and the fluid temperature in the optical cavity during the calibration and sampling phases do not vary significantly, the relationship (3) is simplified as follows:

$$
\frac{\mathbb{L}_{2}, \text { sampling }}{\&_{2} \text {,calib }}=N_{\text {rel }} \times\left[\frac{Q^{0}{ }_{\text {dilu,sampling }}+Q^{0}{ }_{\text {sampling }}}{Q_{\text {dilu, }, \text { calib }}^{0}+Q_{\text {perm }}^{0}}\right]
$$

If the dilution gas flow is fixed in such a way that $Q_{\text {dilusampling }}^{0}+Q_{\text {sampline }}^{0} Q_{\text {dilucalib }}^{0}+Q_{\text {perm }}^{0}$, the value $N_{\text {rel }}$ thus provides a direct reading of the ratio $\frac{\dot{n}_{I_{2}, \text { sampling }}}{\dot{n}_{I_{2}, \text { calib }}}$.

\section{Water vapour and iodine gas generation}

Water vapour samples were prepared from ultrapure water (Milli-Q liquid water). High water vapour amounts were obtained by the mean of a Controlled Evaporator Mixer (CEM) Bronkhorst System. For experiments where water vapour is used as a process gas, the line from the water vapour generator to the cavity and/or to the furnace is heated to ensure that no condensation occurs.

For the iodine calibration and the laboratory simulations, two kinds of iodine generation have been used: the permeation tubes allowed low and medium concentration ranges while the Iodine generator (GI) could generate very high amounts of iodine. 
The temperature of the permeation oven (VICI 150-C) was varied between $30^{\circ} \mathrm{C}$ to $100{ }^{\circ} \mathrm{C}$ which leads to a molecular iodine concentration range $\sim 1$ to $140 \mathrm{nmol} / \mathrm{l}$ if no dilution were performed apart from the Ar carrier gas going through the permeation oven $(0.4 \mathrm{Nl} / \mathrm{min})$.

To reach higher iodine concentration ranges, which are more representative of a severe accident, another kind of homemade generation system based on the solid/vapour equilibrium of iodine was used. This equilibrium is well described by the SANEMASA relation which gives the iodine partial Pressure, $\mathrm{P}$ (in Pa), as a function of absolute temperature T (in K) ${ }^{(47)}$ : $\log \left(\mathrm{P} . \mathrm{T}^{3 / 2}\right)=16.945-(3464 / \mathrm{T})$

The temperature of the solid iodine can be regulated from 0 up to $110{ }^{\circ} \mathrm{C}$ (below $\mathrm{I}_{2}$ fusion) and the carrier gas flow rate up to $0.7 \mathrm{Nl} / \mathrm{min}$. The achieved iodine molar flow under our experimental conditions ranged from $\sim 4 \times 10^{-9}$ up to $5 \times 10^{-7} \mathrm{~mol} / \mathrm{s}(\sim 0.3 \mu \mathrm{mol} / \mathrm{l}$ to $40 \mu \mathrm{mol} / \mathrm{l})$.

For low concentrations, the amount of iodine at the outlet of the permeation oven was measured by trapping the gas in a solution of potassium iodide $(\mathrm{KI})(0.1 \mathrm{M})$. The $\mathrm{I}_{3}{ }^{-}$ion formed by the dissolving of $\mathrm{I}_{2(\mathrm{~g})}$ in KI was assayed by UV-visible spectrometer (Agilent 8453 ) ${ }^{(7)}$. For higher concentrations, the generated iodine gas was trapped in $1 \mathrm{M}$ sodium hydroxide solution. The solutions were then analyzed at regular intervals by inductively coupled plasma-mass spectrometry (ICP-MS).

\section{Laboratory aerosol generation and monitoring}

The laboratory aerosols used in this work were generated by atomization of the salt solution in ultrapure water using a constant output atomizer (TSI Model 3076). The mean particle size of the generated aerosol can be varied between 0.02 and $0.3 \mu \mathrm{m}$ by atomizing and evaporating the solvent: the atomized aerosols were first dried by passing through a Silica Gel dryer (TSI, Model 3062). The particle number concentration and the aerosol size distribution were varied by changing the concentration of the solution. Materials such as sodium chloride, potassium chloride, sodium carbonate were used to generate solid particle aerosols.

A TSI NanoScan Scanning Mobility Particle Sizer (SMPS) Model 3910 was used to size and to count particles from 10 to $420 \mathrm{~nm}$ in 13 measuring channels. Furthermore, we utilized other devices for characterizing fine and ultrafine particles: PEGASOR ${ }^{\circledR}$ particle sensor PPS-M is a real time continuous detector for mass and number measurements. The instrument is based on particle charging and electrical detection of charged particles. Its high sensitivity, its wide dynamic range $\left(1 \mu \mathrm{g} / \mathrm{m}^{3}-250 \mathrm{mg} / \mathrm{m}^{3}\right)$ and its fast response time $(10 \mathrm{~Hz}, 0.1 \mathrm{~s})$ allowed to probe particulate matter (PM) from industrial dusts to diesel exhaust particles from engines. At first, the output signal of the Pegasor Particle Sensor (PPS) was calibrated with diesel engine exhaust 
(with typical mean size distribution: $D_{n} \sim 40-65 \mathrm{~nm}$ ) to deliver either the mass or the number concentration of exhaust aerosol. (PPS) calibration depends on the size distribution. As the sensor response is linear, only one correction factor can be used to fine tune the calibration ${ }^{(48)}$. The size distribution of the particles studied in this work is quite similar to that from diesel combustion engines then we can continue to use the same initial model calibration used for automotive application. Therefore no correction factor is introduced for the current measurements (correction factor for Mass and Number $\approx 1$ ). In order to measure the accurate aerosol mass concentrations, we rather used a Tapered Element Oscillating Microbalance (TEOM) analyzer that determines the mass of particles collected on a filter by continuous monitoring the corresponding frequency changes of a vibrating tapered element. As particles accumulate on the filter cartridge, the natural frequency of oscillation of the tapered element decreases.

\section{Instrument performance: Stability, Precision, and Detection Limit}

We observed excellent stability over time of the IBB-CEAS signals even in the presence of aerosols.

By introducing into the cell a known iodine concentration and using the absolute absorption cross-section of $\mathrm{I}_{2}$ measured by Saiz-Lopez et al. ${ }^{(49)}$, we can estimate the ratio $\frac{1-R(\lambda)}{d}$ from equation (1).

Fig. 2a shows a typical example of raw IBB-CEAS signals for an empty cavity $I_{0}$ (blue color) and for a cavity filled with an iodine concentration $\left(\left[\mathrm{I}_{2}\right] \sim 1.1 \times 10^{13}\right.$ molecules.cm $\left.{ }^{-3}\right) I_{\text {sample }}$ (red color). In Fig. $\mathbf{2 b}$ the absolute cross-section of iodine is displayed in the wavelength range $500<\lambda<550 \mathrm{~nm}$ as reported by Saiz-Lopez et al. ${ }^{(49)}$. As a result, we deduce the ratio $\frac{1-R(\lambda)}{d}$ given in Fig. 2c. Neglecting the mirror protection flow and assuming that the optical absorption length $d(\lambda)$ is constant and equal to the length of the cavity, we can estimate a lower limit of the reflectivity of the mirrors drawn in Fig. $2 d(R \sim 0.998)$.

The theoretical sensitivity of our setup is estimated from the noise in a baseline $\Delta\left(I_{0} / I\right)$ assuming a mirror reflectivity $\mathrm{R} \sim 0.998$ and a cavity length $50 \mathrm{~cm}$. For $10 \mathrm{~s}$ acquisition time, a noise level of $\sim 5 \times 10^{-8} \mathrm{~cm}^{-1}$ is obtained in the LED emitting range. Taking into account the maximum absorption cross-section of $\mathrm{I}_{2}$ at $533 \mathrm{~nm}$ measured by Saiz-Lopez et al. ${ }^{(49)}$ ( $\sigma=$ $(4.24 \pm 0.50) \times 10^{-18} \mathrm{~cm}^{2} \times$ molecule $\left.{ }^{-1}\right)$, the minimum detectable concentration of iodine is about $1 \times 10^{10}$ molecules $\times \mathrm{cm}^{-3}$. So, we would estimate the theoretical detection limit to be about $2 \times 10^{-2} \mathrm{nmol} / \mathrm{l}$. The measured detection limit is rather $\sim 5 \times 10^{-2} \mathrm{nmol} / \mathrm{l}$, i.e., $\sim 1 \mathrm{ppbv}$. As expected 
and as discussed by Thalman and Volkamer ${ }^{(38)}$ and Thalman et al. ${ }^{(39)}$, the experimental limit of detection (LOD) is about $2 \times$ the theoretical noise limit $\left(\mathrm{LOD}_{\exp } \approx 2-\sigma\right.$ Root Mean Square (RMS) residual noise).

The numerical accumulation mode of single-exposure spectra allows improving the signal-tonoise ratio significantly.

The effective path length $d$ was measured by introducing a known concentration of $\mathrm{NO}_{2}$ into the cell. This has been done firstly by running $\mathrm{NO}_{2}$ through the cell without the mirror flows. In this way $d$ will be equal to the physical distance between the two mirrors $(50 \mathrm{~cm})$. From the known $\sigma, n, d, I, I_{0}$ and $B g R$ can be calculated for the mirrors under these conditions. If the mirror flow is then turned on, having adjusted the concentration of $\mathrm{NO}_{2}$ for the additional dilution from the mirror flow, $d$ is calculated to reproduce the same $R$. Under the following conditions (mirror flow $\sim 310 \mathrm{cc} / \mathrm{min}=0.31 \mathrm{Nl} / \mathrm{min}$ and $\mathrm{NO}_{2}$ flow $\sim 3 \mathrm{Nl} / \mathrm{min}$ ), the effective path length $d$ was found to be $\sim 37 \mathrm{~cm}$.

Another improvement of the instrument consisted in extending the dilution range from 2 to 35 $\mathrm{Nl} / \mathrm{min}$ leading to a dilution factor of $\sim 18$ times. In this work we were able to extend the concentration range of $\mathrm{I}_{2}$ measured by IBB-CEAS (from $\sim 5 \times 10^{-2} \mathrm{nmol} / \mathrm{l}$ to $\sim 2 \mu \mathrm{mol} / \mathrm{l}$ ) which is the iodine concentration range of IRSN programs and in Severe Accident conditions in the reactor containment building.
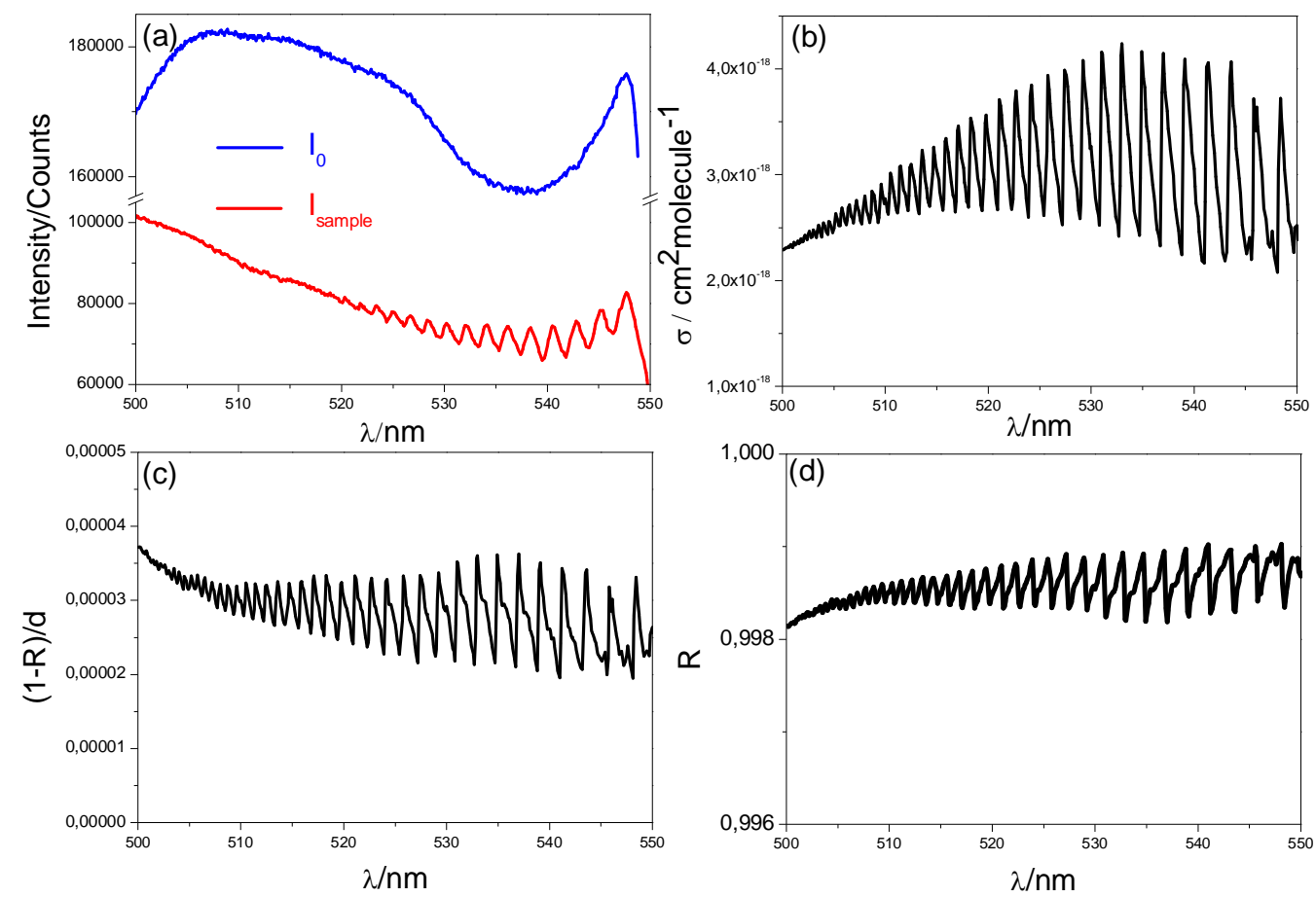

Figure. 2 (a) The intensity of transmitted light recorded with only the carrier gas inside the cavity $I_{0}$ (blue curve) and $I_{\text {sample }}$ the intensity of transmitted light recorded with sample gas inside the cavity (red curve). (b) The absorption cross-section from Saiz-Lopez et al. ${ }^{(49)}$. (c) 
The function $\frac{1-R(\lambda)}{d}$ deduced from equation (1) using $\mathrm{I}_{2}$ species and $\sigma$ from Saiz-Lopez et al. (49). (d) The reflectivity $R$ approximated by omitting the shortening of the value of $\mathrm{d}$ by the mirror protection flow.

\section{IV. $\quad I_{2}$ in the presence of water vapour}

Good knowledge of the weak water lines in this visible range is required for the retrieval of other atmospheric gases absorbing in the same spectral range, as for instance in this work in the case of iodine in the presence of very high water vapour concentrations.

\section{Presence of $\mathrm{H}_{2} \mathrm{O}$ absorption features}

In the infrared, the spectroscopy of water vapour has been studied thoroughly and line parameters, generally of good quality, are available. However, in the visible and near ultraviolet, the absorption of water vapour is very weak and data are rather incomplete. At present, the most complete sets of water vapour line parameters available for this region are those of Coheur and Fally ${ }^{(50,51)}$, between 26000 and $13000 \mathrm{~cm}^{-1}$.

Langridge et al. (40) measured broadband supercontinum cavity enhanced absorption spectroscopy SC-CEAS spectra of the $4 v$ and $4 v+\delta$ polyad vibrational overtones of water vapour in the $620740 \mathrm{~nm}$ wave range. At the best of our knowledge, only two reference report measurements of water vapour lines in this spectral region: Coheur and Fally ${ }^{(50,51)}$ between 26000 and $13000 \mathrm{~cm}^{-1}(384-769 \mathrm{~nm})$ and Langridge et al. ${ }^{(40)}$ between 620 and $740 \mathrm{~nm}$. Given our spectral range of interest $(500-550 \mathrm{~nm})$, only the line intensities reported by Coheur and Fally will be considered for comparison with our experimental spectra recorded in presence of water vapour.

The experimental water vapour spectra (Fig. 3a) have been recorded by the same IBB-CEAS absorption technique. Water vapour has a broadband absorption spectrum. This continuum spectrum has two weak bands (Fig. 3). The pure water vapour spectra were measured by introducing $22 \%$ of water vapour by volume into the absorption cell (50\% water vapour by volume exit steam generator), in order to allow the observation of weak lines while avoiding condensation on the mirrors, the cell walls and on the gas lines. 


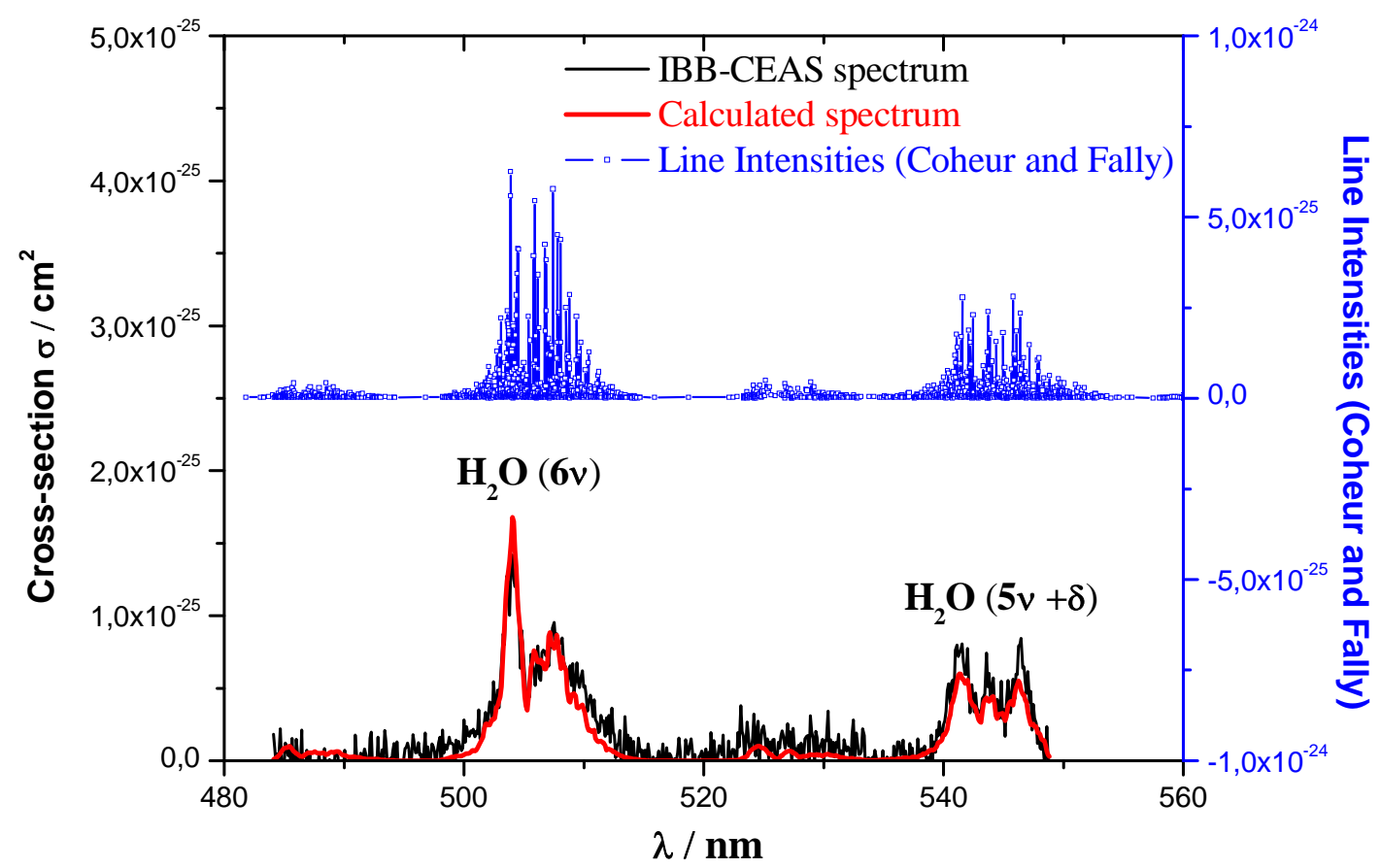

Figure. 3 (a) Upper graph: in blue water vapour line intensities (integrated cross-section) obtained by combining a high-resolution Fourier transform spectrometer with a long-path absorption cell by Coheur and Fally ${ }^{(50,51)}$. Lower graph: $\mathrm{H}_{2} \mathrm{O}$ IBB-CEAS spectrum (this work) in black line, in red is displayed the calculated spectrum using a convolution of the highresolution Fourier transform spectrometer water vapour line intensities ${ }^{(50,51)}$ with square function $\mathrm{FWHM}=1 \mathrm{~nm}$.

http://satellite.mpic.de/spectral atlas

Coheur et al. ${ }^{(50,51)}$ have previously measured water vapour line parameters in the visible and near ultraviolet spectral region 26000-13000 $\mathrm{cm}^{-1}(384-769 \mathrm{~nm})$. The measurements were obtained by combining a high-resolution Fourier Transform Spectrometer (Bruker 120M ®) with a long-path absorption cell $(50 \mathrm{~m})$. The total absorption path was $602.32 \mathrm{~m}$, thus allowing the observation of very weak, previously unobserved, lines. A $450 \mathrm{~W}$ high-pressure xenon arc lamp was used as the light source. Two detectors (a $\mathrm{Si}$-and a $\mathrm{GaP}$ diodes) were used to cover the spectral region investigated. Spectra were recorded at room temperature and at a resolution of $0.06 \mathrm{~cm}^{-1}(0.0015 \mathrm{~nm})$.

The IBB-CEAS water vapour spectra agree satisfactorily with the long-pathlength Fourier transform spectra (Fig. 3b).

The water vapour line cross-sections ${ }^{(50,51)}$ were convoluted by the instrumental function leading to the theoretical spectrum shown in Fig. 3a. In order to achieve good agreement between 
experimental and simulated spectra a square function with a full width at half maximum (FWHM) $1 \mathrm{~nm}$ was introduced in the calculations.

Fortunately, as shown in Fig. 4, the strongest band around $505 \mathrm{~nm}$ being outside the iodine spectral features $(510-550 \mathrm{~nm})$, interferences should remain limited. However, it remains to check if the weaker band in the high wavelength range of the spectrum around $540 \mathrm{~nm}$ (Fig. 3 and Fig. 4) disturbs and influences the quantitative measurements of iodine.

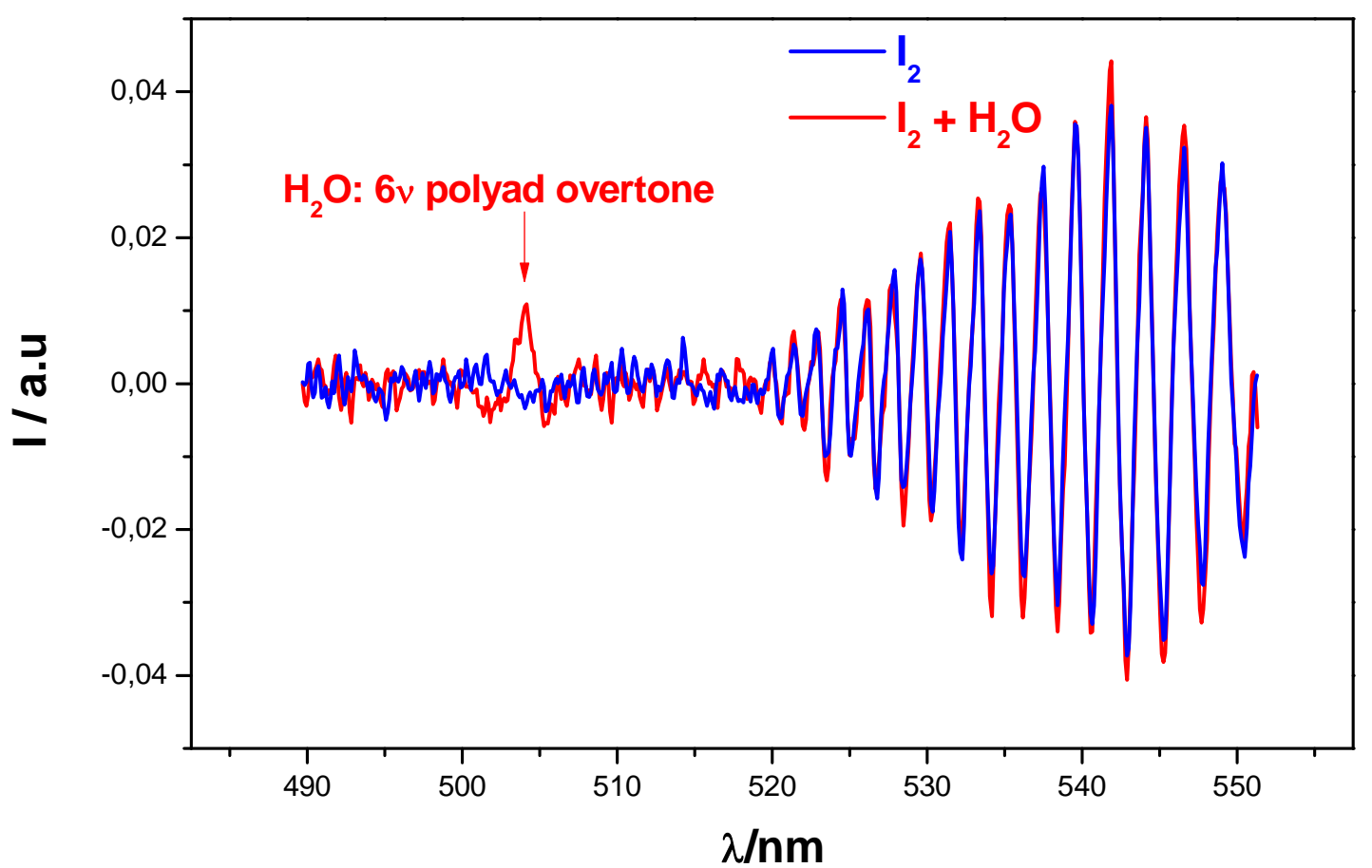

Figure. 4 Blue line: High frequency part of the pure iodine spectrum recorded by IBB-CEAS technique for an iodine concentration of $\sim 18.3 \mathrm{nmol} / \mathrm{l}$ after subtraction of polynomial fit. Red line: the IBB-CEAS spectrum of a mixture of iodine and $35 \%$ water vapour by volume in the mixing line. The $\mathrm{H}_{2} \mathrm{O}$ absorption peak around $505 \mathrm{~nm}$ is clearly visible (for $\mathrm{H}_{2} \mathrm{O}$, there is only "positive" absorption above the polynomial fit), the $\mathrm{H}_{2} \mathrm{O}$ peak at $545 \mathrm{~nm}$ is hidden in $\mathrm{I}_{2}$-structure and is too weak to be visible.

\section{Quantification of $I_{2}$ in the presence of water vapour}

Fig. 5 displays an example of iodine concentration measured without and with water vapour. At the beginning of the experiment, before the addition of water vapour, the iodine concentration is equal to $18.3 \mathrm{nmol} / \mathrm{l}$ represented in Fig. 5 by the blue marks (reference). As water vapour is added, the measured density of iodine is affected and overestimated (red marks). For water vapour by volume less than $15 \%$ in the mixing line, the effect of water vapour on the iodine concentration is negligible as shown in Fig. 5. Above a water vapour volume of 15\%, the overestimation of iodine concentration increases with relative humidity in the mixing line. 
For instance, for a water vapour fraction of $22 \%$ in the mixing line (respectively $35 \%$ ) iodine concentration is overestimated by $10 \%$ ( $30 \%$ respectively). The absorption of water vapour creates an artefact in the iodine concentration measurement by increasing the iodine lines.
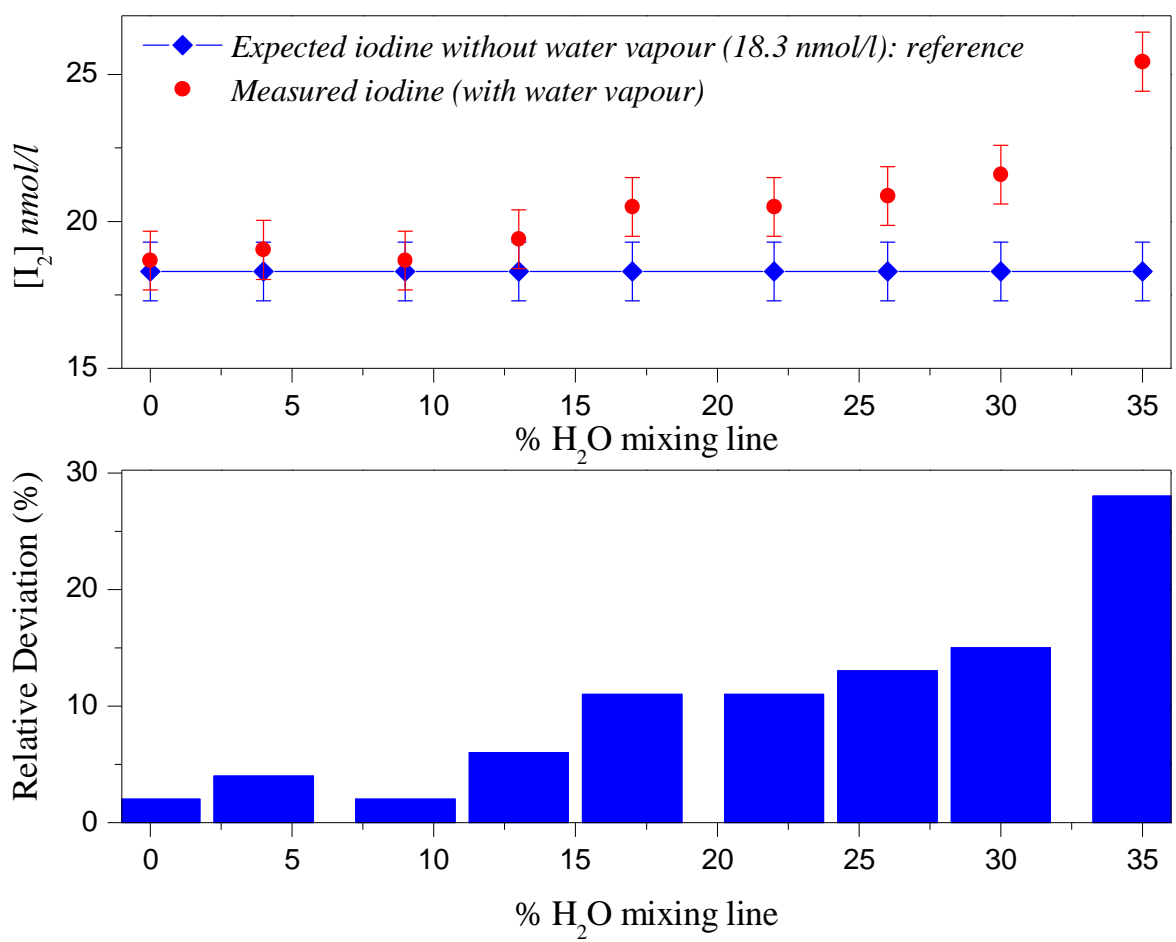

Figure. 5 Water vapour effect on the iodine concentration. Upper panel: blue marks: expected density of iodine (without water vapour), red marks: density of iodine measured in the presence of water vapour obtained by fitting in the range $490-550 \mathrm{~nm}$. Lower panel: the relative deviation from the expected iodine density.

It is obvious that dilution by the argon carrier gas reduces the percentage of water vapour in the mixing line and therefore reduces water vapour interference. However, we showed that if the water vapour fraction is known and does not vary in the experiments, a calibration of the IBBCEAS device in the same conditions will allow to take into account this interference, i.e. the overestimation of $\mathrm{I}_{2}$ concentration at high $\mathrm{H}_{2} \mathrm{O}$ concentrations can be corrected for. This approach completely solves the problem of interference with water.

\section{V. $\quad I_{2}$ in the presence of aerosols}

In order to show the effect of aerosols on iodine measurements, experiments with laboratory generated aerosols of known size and concentration were performed.

\section{Aerosols description}


Fig. 6 displays a typical nanoparticle size distribution of $\mathrm{NaCl}$ aerosol atomized from different concentrations, measured using NanoScan SMPS. For a $\mathrm{NaCl}$ concentration of $0.2 \mathrm{~g} / \mathrm{l}$, the distribution mode is at $27 \mathrm{~nm}$ and the total concentration of aerosols produced is around $2 \times 10^{6}$ particle $/ \mathrm{cm}^{3}$. As displayed in Fig. 6, the concentration and the size of aerosol particles increase with the concentration of the sprayed solution. For the $[\mathrm{NaCl}]=1 \mathrm{~g} / \mathrm{l}($ respectively $[\mathrm{NaCl}]=5$ $\mathrm{g} / \mathrm{l}$ ) the mode is $37 \mathrm{~nm}$ and the total concentration of aerosols particles is $\sim 3.5 \times 10^{6}$ particle $/ \mathrm{cm}^{3}$ (respectively $49 \mathrm{~nm}$ and $\sim 5.5 \times 10^{6}$ particle $/ \mathrm{cm}^{3}$ ). These results are consistent with the nominal concentration provided by the TSI user's manual $\left(\sim 2 \times 10^{6}\right.$ particle $\left./ \mathrm{cm}^{3}\right)$.

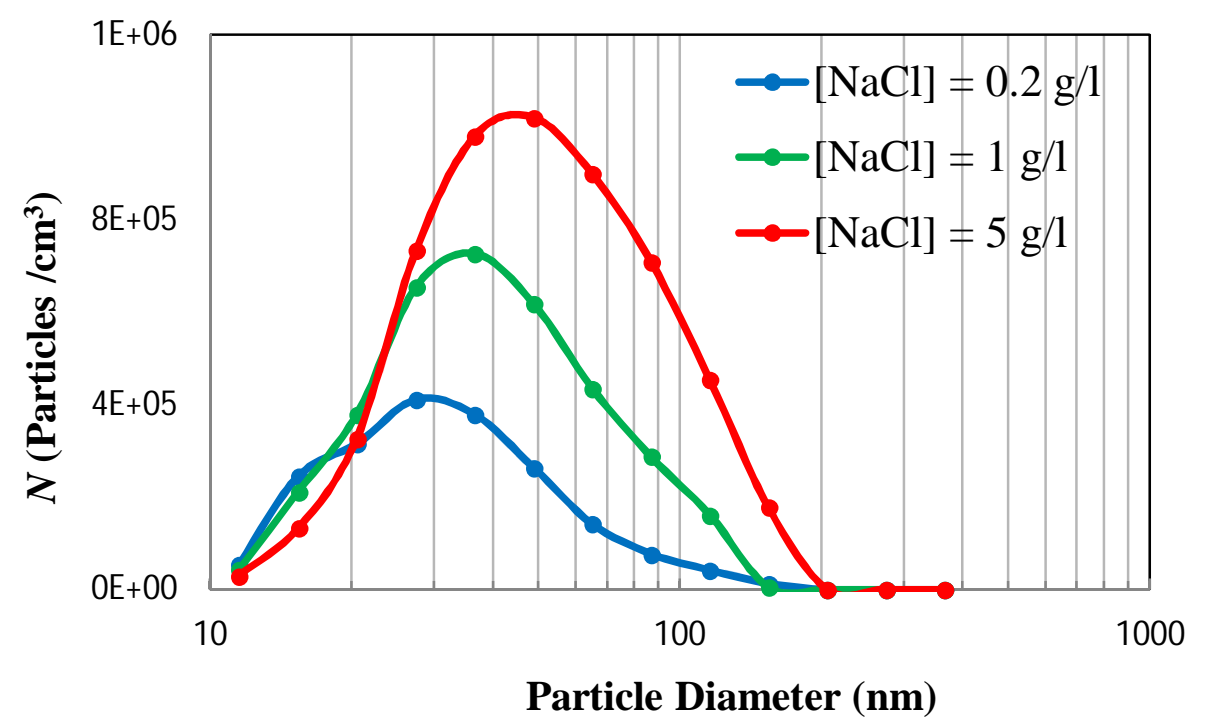

Figure. 6 Atomized $\mathrm{NaCl}$ aerosols measured using NanoScan SMPS. Effect of the solution concentration on the salt particles distribution generated by the Atomizer.

According to the Fig. 7, the distribution of the particles is almost independent of the type of the solute. 


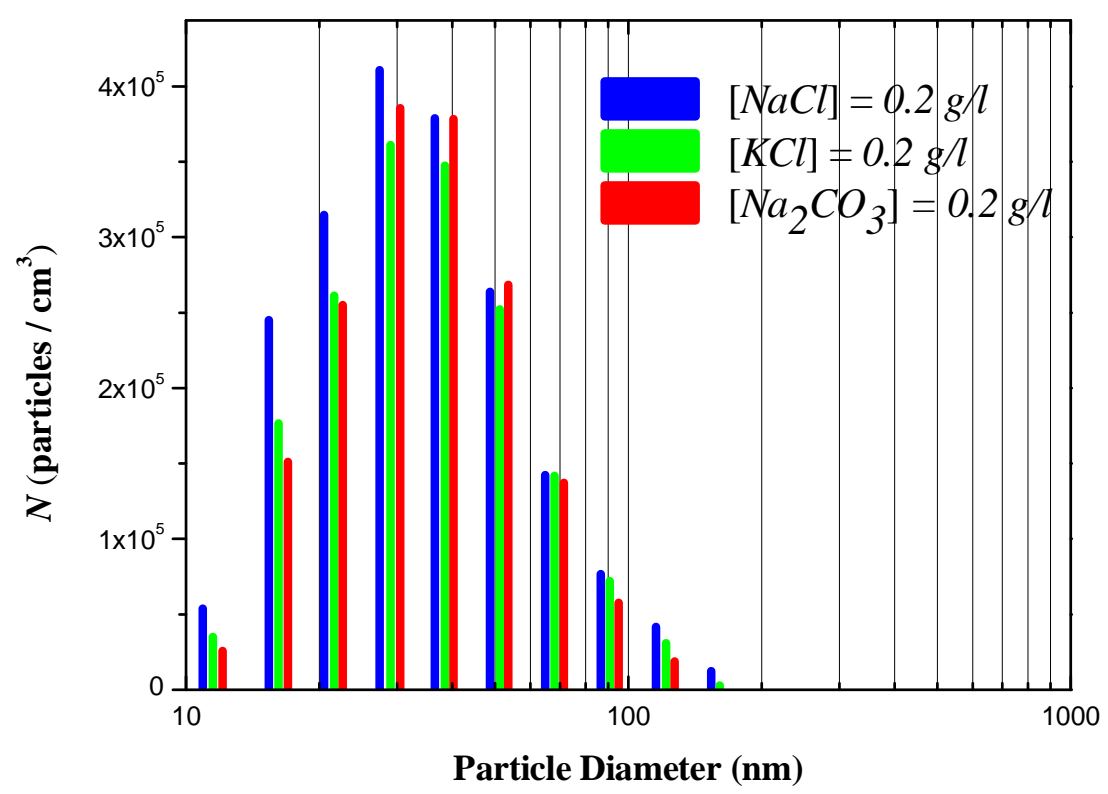

Figure. 7 Effect of the nature of the solute on the size distribution of generated aerosols.

Table 1 summarizes particle number measurements recorded using both Nano Scan SMPS and PPS and mass concentration monitoring analyzed using a TEOM. The particle number measurements recorded by the two instruments Nano Scan and PEGASOR remain in the same order of magnitude. We observe that the number of particles measured by the PEGASOR is slightly higher than the TSI Nano Scan SMPS; this difference can be explained by the different particle size range of the two analyzers. In fact, the particle size detected by the PEGASOR ranges from few nanometres up to $2.5 \mu \mathrm{m}$ while, as we have seen above, that of Nano Scan stops at $420 \mathrm{~nm}$ and therefore the PPS is capable of detecting wider size range of particles. $A$ priori, as the concentration of the TSI solution increases, the number of particles with a size above the Nano Scan detection limit increases as well.

According to the analyzes made by TEOM and presented in Table 1, the mass concentrations of aerosols produced in the concentration range of the atomized solutions tested in this work varied between few $\mathrm{mg} / \mathrm{m}^{3}$ and $\sim 100 \mathrm{mg} / \mathrm{m}^{3}$ which correspond to the concentration range encountered in the containment vessel in severe accident conditions.

Measurements made by the different analyzers confirm the same order of magnitude between aerosols produced by both $\mathrm{NaCl}$ and $\mathrm{Na}_{2} \mathrm{CO}_{3}$ solutions in terms of number of particles and size population (Fig. 7 and Table. 1). 
Table. 1 Mass and particle number concentrations of aerosols produced by the TSI generator measured through TEOM, PEGASOR and NanoScan SMPS sensors, respectively, for different $\mathrm{NaCl}$ and $\mathrm{Na}_{2} \mathrm{CO}_{3}$ concentrations. Each data point represents the average and standard deviation of measurements.

\begin{tabular}{|c|c|c|c|c|c|c|}
\hline \multirow{3}{*}{$\begin{array}{c}\text { [TSI } \\
\text { stock } \\
\text { solution] } \\
(\mathrm{g} / \mathrm{l})\end{array}$} & \multicolumn{3}{|c|}{$\mathrm{NaCl}$ aerosols } & \multicolumn{3}{|c|}{$\mathrm{Na}_{2} \mathrm{CO}_{3}$ aerosols } \\
\hline & \multicolumn{2}{|c|}{$N\left(\right.$ particles.cm $\left.{ }^{-3}\right)$} & \multirow{2}{*}{$\begin{array}{c}\begin{array}{c}\text { Density } \\
\left(m g . m^{-3}\right)\end{array} \\
\text { TEOM }\end{array}$} & \multicolumn{2}{|c|}{$N\left(\right.$ particles.cm $\left.{ }^{-3}\right)$} & \multirow{2}{*}{$\begin{array}{c}\begin{array}{c}\text { Density } \\
\left(m g \cdot m^{-3}\right)\end{array} \\
\text { TEOM }\end{array}$} \\
\hline & $\begin{array}{c}\text { NanoScan } \\
\text { SMPS }\end{array}$ & PEGASOR & & $\begin{array}{c}\text { NanoScan } \\
\text { SMPS }\end{array}$ & PEGASOR & \\
\hline 0.1 & $(1.0 \pm 0.1) \times 10^{6}$ & $(1.5 \pm 0.1) \times 10^{6}$ & $1.5 \pm 0.5$ & & $(1.2 \pm 0.1) \times 10^{6}$ & $1.9 \pm 0.5$ \\
\hline 0.2 & $(1.9 \pm 0.1) \times 10^{6}$ & $(2.4 \pm 0.1) \times 10^{6}$ & $2.4 \pm 0.5$ & $(1.6 \pm 0.1) \times 10^{6}$ & $(2.4 \pm 0.1) \times 10^{6}$ & $2.5 \pm 0.5$ \\
\hline 0.3 & & $(2.9 \pm 0.1) \times 10^{6}$ & $2.8 \pm 0.5$ & & $(2.7 \pm 0.1) \times 10^{6}$ & $3.3 \pm 0.5$ \\
\hline 0.5 & & $(3.8 \pm 0.1) \times 10^{6}$ & $4.9 \pm 0.5$ & & $(4.1 \pm 0.1) \times 10^{6}$ & $4.8 \pm 0.5$ \\
\hline 1 & $(3.6 \pm 0.1) \times 10^{6}$ & $(5.7 \pm 0.1) \times 10^{6}$ & $9.8 \pm 0.5$ & & $(5.7 \pm 0.1) \times 10^{6}$ & $10.5 \pm 0.5$ \\
\hline 2 & $(4.3 \pm 0.1) \times 10^{6}$ & $(8.1 \pm 0.1) \times 10^{6}$ & $20.0 \pm 0.5$ & $(3.8 \pm 0.1) \times 10^{6}$ & $(8.4 \pm 0.1) \times 10^{6}$ & $21.0 \pm 0.5$ \\
\hline 5 & & $(18.5 \pm 0.1) \times 10^{6}$ & $52.3 \pm 0.5$ & & $(22.4 \pm 0.1) \times 10^{6}$ & $50.5 \pm 0.5$ \\
\hline 10 & & $(29.0 \pm 0.1) \times 10^{6}$ & $100 \pm 0.5$ & & $(31.0 \pm 0.1) \times 10^{6}$ & $98.6 \pm 0.5$ \\
\hline
\end{tabular}

\section{Light extinction}

For measurements in the ambient atmosphere, aerosols are likely to be the largest contributor to extinction and thus reduce the path length in the cavity. The optical extinction coefficient $\alpha(\lambda)$ due to a sample present inside the cavity can be expressed as follows:

$\alpha(\lambda)=\alpha_{\text {gas }}(\lambda)+\alpha_{\text {aerosol }}(\lambda)$

where the extinction coefficient describing the light extinction due to aerosols inside the cell can be deduced from Eq. (1):

$\frac{I_{0}-B g}{I-B g}-1=\frac{d}{1-R} \alpha_{a e r} \approx \alpha_{a e r}^{f r a c}$

$\alpha_{\text {aer }}^{\text {frac }}$ is the "fractional optical loss" or "fractional extinction" of aerosols. Remember that in order to extract the true value of $\alpha_{a e r}$ it is necessary to measure the reflectivity of the cavity mirrors $R(\lambda)$ and the distance $d(\lambda)$ of the sample in the cell.

The aerosols were drawn into the cavity cell at a nominal flow rate of $3 \mathrm{Nl} / \mathrm{min}$ for the aerosol optical extinction measurements. Comparison of the aerosols extinction coefficients (2-min averages) measured by IBB-CEAS is displayed in Fig. 8 for different salt concentrations. In the spectral range of interest, the aerosol extinction coefficients are almost constant which allows using the DOAS approach. As we have concluded before, the higher the concentration of the 
sprayed solution the higher the concentration and the size of the aerosol particles, therefore the scattering and absorption of aerosols, $\alpha_{\text {aerosol }}(\lambda)$, increase as shown in Fig. 8.

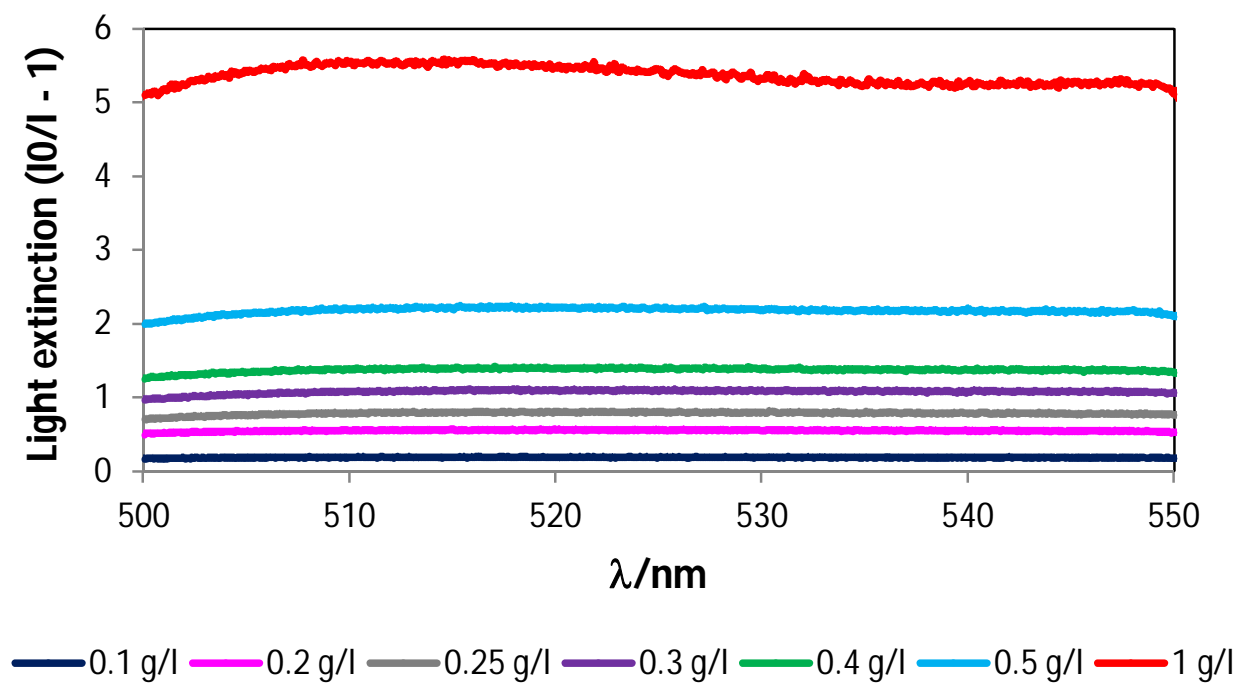

Figure. 8 The coefficient $\frac{I_{0-B g}}{I-B g}-1$, describing light extinction due to aerosols inside the cell for different salt $(\mathrm{NaCl})$ concentrations.

In Fig. 9, we plot the extinction coefficient for different types of aerosols for the same mass density of $0.3 \mathrm{~g} / \mathrm{l}$. Approximately, the extinction coefficients have the same order of magnitude. From Fig. 9, a trend appears: the extinction coefficient of $\mathrm{Na}_{2} \mathrm{CO}_{3}$ particles is less than that of $\mathrm{NaCl}$ particles. The similarity in the size and the number of aerosols cannot explain this different behaviour; however the different morphology and structure of the two aerosols observed with images taken on Scanning Electron Microscope (SEM) ${ }^{(52)}$ and Transmission Electron Microscopy ${ }^{(53)}$ may explain this trend. 


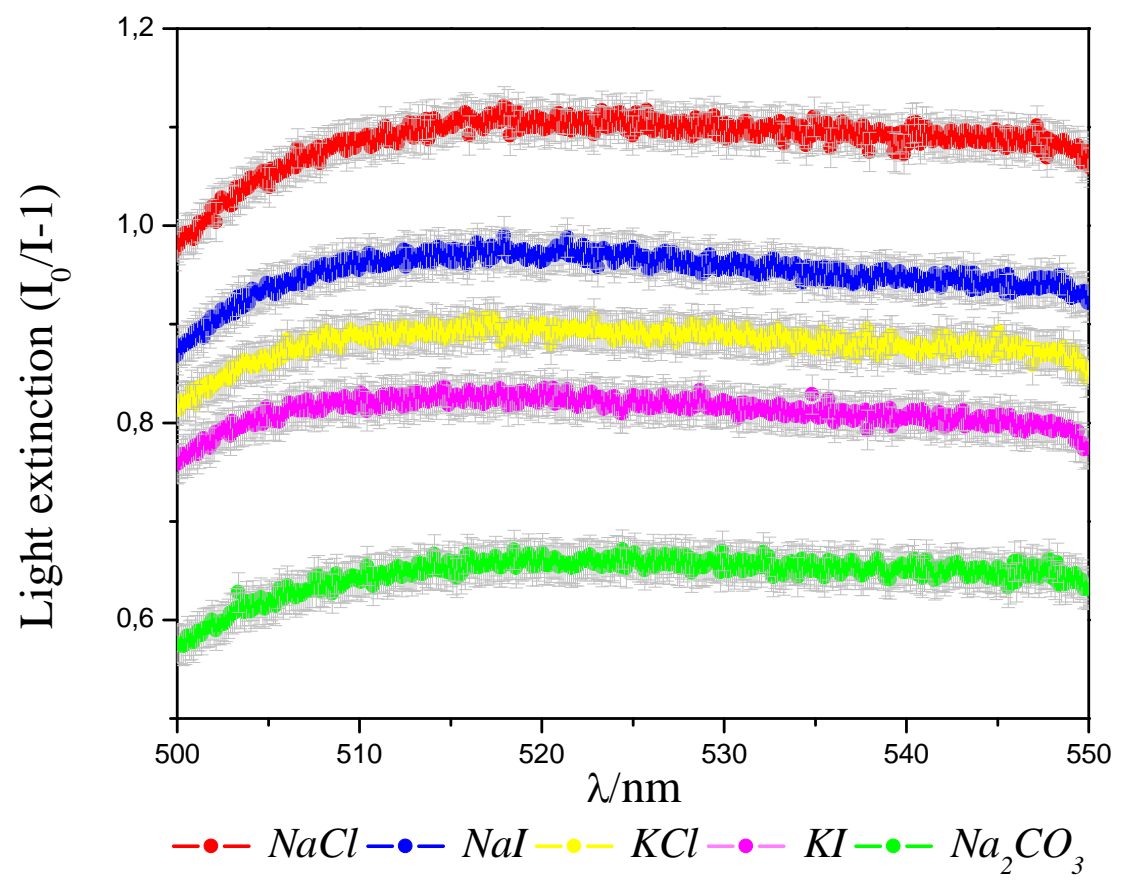

Figure. 9 Effect of the nature of the solution on the light extinction coefficient $\left(\frac{I_{0-} B g}{I-B g}-1\right)$ for the same mass density of $0.3 \mathrm{~g} / \mathrm{l}$.

\section{Quantitative IBB-CEAS measurements of $I_{2}$ in the presence of aerosols}

The $\mathrm{I}_{2}$ concentration has been measured as explained above (fitting between $490-550 \mathrm{~nm}$ ) and can be compared with the expected concentration. To illustrate the effect of aerosols on the measured iodine concentration, we consider in the mixing line an iodine concentration of $~ 15.6$ nmol/l represented in Fig. 10 by blue dots. Aerosols of different nature $\left(\mathrm{KCl}, \mathrm{NaCl}, \mathrm{Na}_{2} \mathrm{CO}_{3}\right)$ were gradually added and mixed with iodine. The discrepancy between the measured iodine concentration with and without aerosols is reported as a function of the aerosol fractional extinction. For low aerosol extinction $\alpha<1.5$ (equivalent to a concentration of $\mathrm{NaCl}$ sprayed solutions up to $\sim 0.4 \mathrm{~g} / \mathrm{l}$ ), the discrepancy between the iodine concentration with and without aerosols does not exceed $10 \%$. The aerosol effect is negligible for these aerosol concentrations. However, with extinction coefficient $\alpha>2$, the underestimation of iodine concentration becomes significant. For example, for $\alpha \sim 5.4$ ([NaCl] $=1 \mathrm{~g} / \mathrm{l}$ in red marks), the deviation is estimated at about $32 \%$. Note that for sodium carbonate aerosols (open yellow marks) a significant deviation from the expected iodine concentration occur for higher concentration of $\mathrm{Na}_{2} \mathrm{CO}_{3}$ sprayed solution compared to $\mathrm{NaCl}$. For solution $\left[\mathrm{Na}_{2} \mathrm{CO}_{3}\right]=1 \mathrm{~g} / \mathrm{l}, \alpha \sim 3.5$, (respectively $2 \mathrm{~g} / \mathrm{l}, \alpha \sim 7.2$ ), the deviation from the expected value, without aerosols, does not exceed $15 \%$ (respectively $\approx 38 \%$ ). We can conclude less disturbance of iodine with sodium 
carbonate; this result is consistent with the lower extinction coefficient of $\mathrm{Na}_{2} \mathrm{CO}_{3}$ compared to $\mathrm{NaCl}$ aerosols as is clearly shown in Fig. 9.

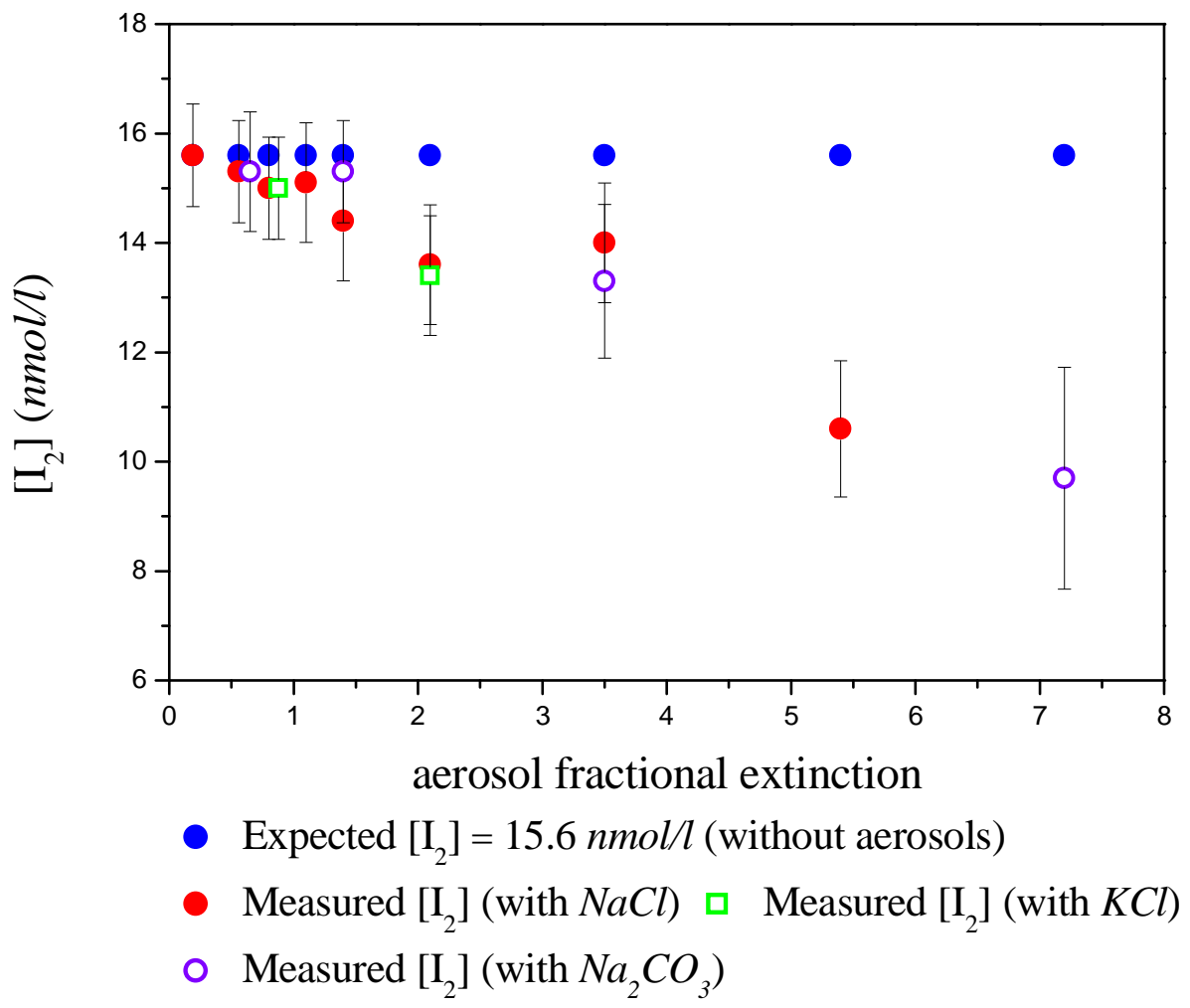

Figure. 10 Effect of the $\left(\mathrm{NaCl}, \mathrm{KCl}\right.$ and $\left.\mathrm{Na}_{2} \mathrm{CO}_{3}\right)$ aerosols on the $\mathrm{I}_{2}$ concentrations: Measured $\mathrm{I}_{2}$ concentrations versus different aerosol fractional extinction.

We can take advantages of the great dilution flexibility to correct deviations from the expected values by reducing the aerosol concentrations.

It follows that the effects of water vapour and aerosols on iodine are opposite: the presence of high concentration of water vapour tends to increase the retrieved concentration of iodine while the presence of aerosols tends to lower it.

Recently we carried out experiments in the presence of both aerosols and water vapour (humidified aerosols). In some cases, these opposite effects completely cancel each other.

\section{Coupling of IBB-CEAS setup to a flow reactor $-I_{2}$ release monitoring in presence of aerosols of nuclear interest and water vapour}

Several studies over the past 20 years were focused mainly on Cs re-vaporization behaviour from stainless steel surfaces (deposits by condensation and/or aerosol deposition) ${ }^{(54,55)}$. Such research activities are incomplete or not entirely representative of severe accident conditions. 
In the framework of the French MIRE program, the possible re-vaporization of iodine species deposited on the surface of the reactor coolant system was investigated in order to assess the potential delayed iodine releases. In this view, a recent study focused on the re-vaporization of CsI deposited in water vapour/air atmosphere up to $750{ }^{\circ} \mathrm{C}$ has shown a significant release of gaseous $\mathrm{I}_{2}{ }^{(56)}$. Complementary to this study, the IBB-CEAS setup was implemented in the revaporization test device in order to monitor iodine release kinetics.

As described by D. Obada et al. ${ }^{(56)}$, CsI deposits were obtained by aerosols impaction at room temperature on oxidized coupons placed in an exposure cell connected to an aerosol generator (AGK 2000, Palas). A deposition of a few $\mathrm{mg} / \mathrm{cm}^{2}$ can be achieved within several hours.

The re-vaporization device (Fig. 11) is a high temperature furnace (WATLOW ceramic heater CF-964255) which contains an alumina tube (45 cm long, $27 \mathrm{~mm}$ inner diameter). A $304 \mathrm{~L}$ stainless steel coupons $(8 \times 15 \times 2 \mathrm{~mm})$ containing the deposit sample of caesium iodide (CsI) (typical mass: $\mathrm{m}_{\mathrm{CsI}} \sim 4.3 \mathrm{mg}$ ) was placed at the center of the tube. The sample was heated up to a temperature of $750{ }^{\circ} \mathrm{C}$ with a heating rate of $5^{\circ} \mathrm{C} / \mathrm{min}$, then the temperature was maintained for 1 hour at a temperature of $750{ }^{\circ} \mathrm{C}$ before cooling down by natural convection. During the thermal heating cycle, the sample is swept by a low carrier gas flow either composed of synthetic air $(53 \mathrm{mNl} / \mathrm{min})$ or water vapour/argon mixture (using a total flow rate of 200 $\mathrm{mNl} / \mathrm{min}$ : $80 \%$ water vapour and $20 \% \mathrm{Ar}$ ).

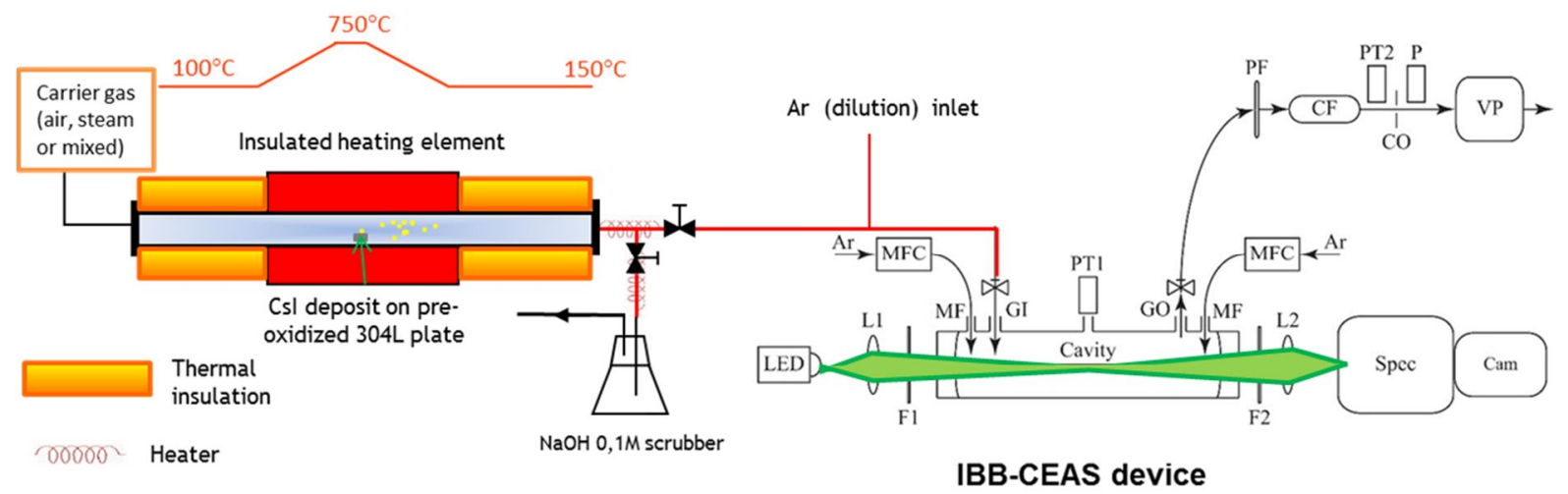

Figure. 11 RIGolo device coupled with on-line optical gaseous molecular iodine monitoring by IBB-CEAS. MFC mass flow controller, Ar argon, $L E D$ light-emitting diode, $L 1$ lens, $L 2$ lens, $F 1$ Thorlabs FGL495 optical filter, $F 2$ Thorlabs FES0550 optical filter, $M F$ mirror flow, $G I$ gas inlet, $G O$ gas outlet, $P T 1, P T 2$ pressure meter and thermocouple, $C F$ charcoal filter, $C O$ critical orifice, $P$ pressure meter, $V P$ vacuum pump, Spec spectrometer, Cam camera.

The vaporized sample or/and generated gas from the heated sample are transported by the carrier gas to the outlet line which is connected to the IBB-CEAS device via the sampling 
line.The wall losses in the outlet line are negligible. A dilution flow rate of $2.5 \mathrm{Nl} / \mathrm{min}$ was applied and the IBB-CEAS signal was accumulate over $30 \mathrm{~s}$. For some tests, an aerosol filter was inserted in the line outlet before the IBB CEAS device (porosity $5 \mu \mathrm{m}$ ). This filter was dedicated to trap sub-micrometric and micrometric particles for surface analysis. The samples were analyzed with the semi-quantitative Scanning Electron Microscopy Energy-Dispersive Xray Spectrometry SEM-EDX method.

It follows from the experimental conditions described above that the fraction of water vapour at the outlet of the furnace can vary from $0 \%$ up to $80 \%$; this corresponds to a range of water vapour fraction in the mixing line of $0 \%$ to $5 \%$ taking into account the dilution. The amount of water vapour in the mixing line is very low and therefore should not affect the quantification of the molecular iodine released to within $10 \%$ (see section IV.2).

In the case of aerosols, if one assumes the total mass of CsI released ( $\mathrm{m} \approx 4.3 \mathrm{mg}$ ) and considering nanometric and micromectric particles of diameter between 0.3 and $2 \mu \mathrm{m}$ (see Fig. 12) we can estimate the total number of particles to $\sim 2 \times 10^{9}$. Finally, taking a flow in the reactor of $0.2 \mathrm{Nl} / \mathrm{min}$, the concentration of particles during the release phase (duration $\sim 1$ hour) can be estimated between $\sim 2 \times 10^{5}$ and $5 \times 10^{6}$ particles. $\mathrm{cm}^{-3}$. A density of CsI, $\rho_{\mathrm{CsI}}=4.5 \mathrm{~g} . \mathrm{cm}^{-3}$, was used for this approximate estimate. The lower limit of the aerosol concentrations is well below the concentrations that have been found to influence the retrieved $\mathrm{I}_{2}$ concentration, however for the upper limit, the effect of aerosols might be noticeable and precautions should be taken in the presence of such aerosol concentrations (see section V). 

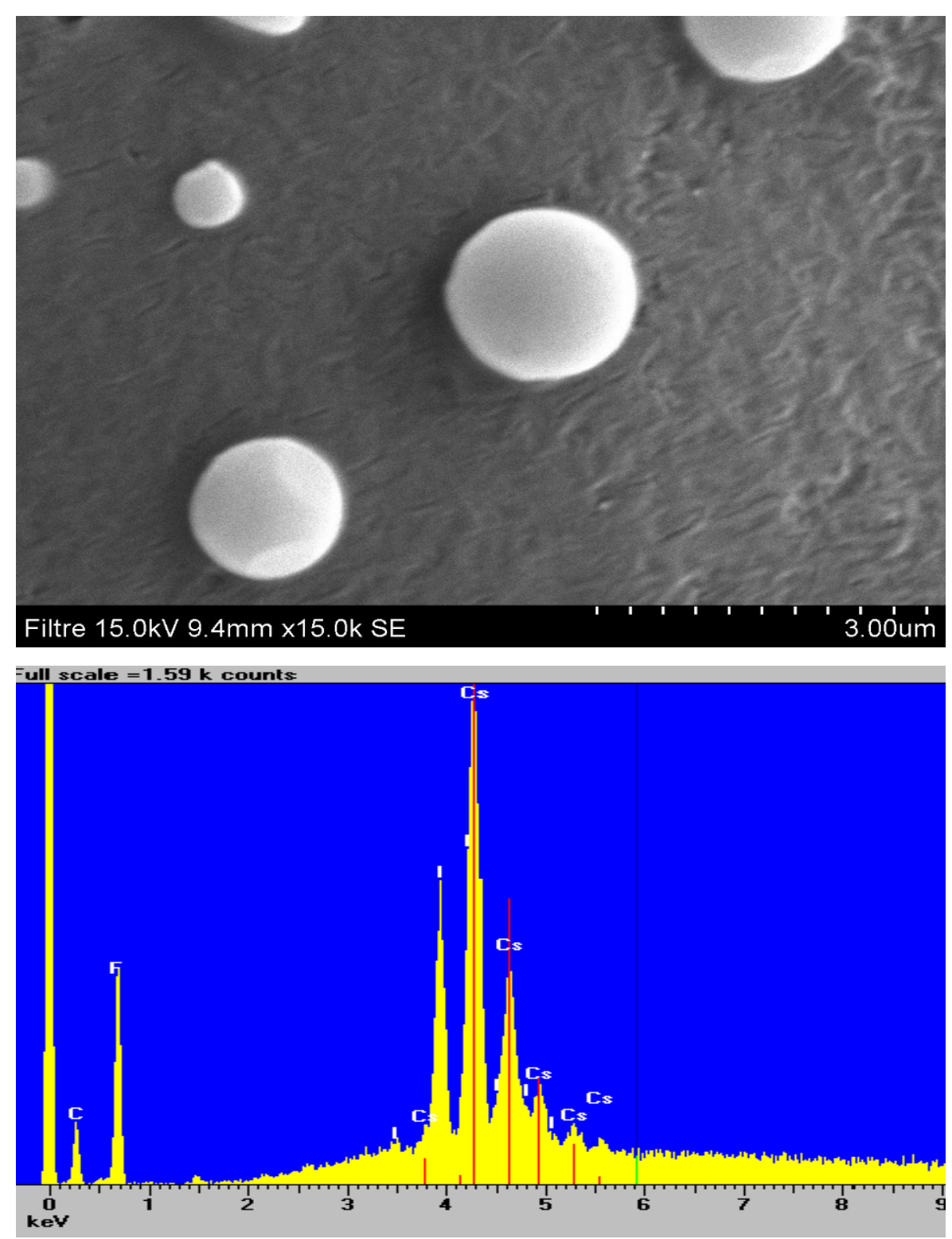

Figure. 12 Characterization of individual submicrometre aerosol particles collected in a PTFE filter, by the SEM-EDX method. The upper image describes the morphology of the Cs-I particles, the lower is the EDX Spectrum.

The first experiments were conducted using air as the process gas (Fig. 13 and blue curve in Fig. 14) and confirm the release of large amounts of gaseous iodine.

In the experiment shown in Fig. 12, we used a reference iodine spectrum produced by the permeation tubes maintained at a temperature $\mathrm{T}^{\text {permeation }}=80^{\circ} \mathrm{C}$ with an argon carrier gas $\mathrm{Q}^{A r}$ ${ }^{\text {flow }}=0.4 \mathrm{Nl} / \mathrm{min}$. The calibration concentration was $\left[\mathrm{I}_{2}\right] \approx 5 \mathrm{nmol} / \mathrm{l}$ corresponding to a furnace temperature about $\sim 550^{\circ} \mathrm{C}$. 


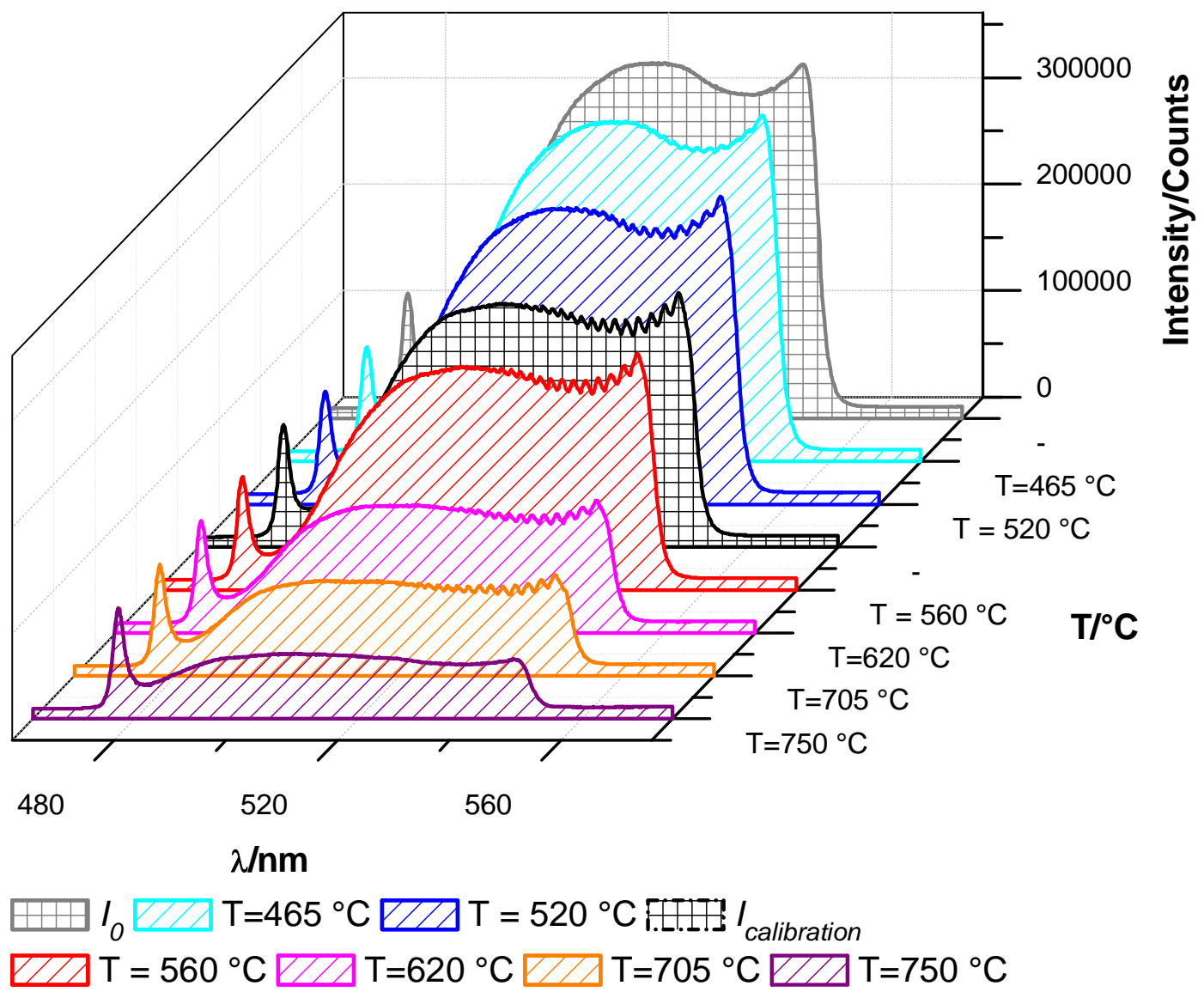

Figure. 13 Intensity of the transmitted light recorded with iodine re-vaporized for different temperature of the furnace. For calibration measurements, a known external source of molecular iodine was used. The calibration concentration was $\left[\mathrm{I}_{2}\right] \approx 5 \mathrm{nmol} / \mathrm{l}$ corresponding to a furnace temperature about $\sim 550{ }^{\circ} \mathrm{C}$. The calibration in the middle of the concentration range of iodine is plotted in black dotted line.

As shown in Fig. 13 and Fig. 14, for low temperatures the amount of the re-vaporized iodine is low and increases as the temperature of the oven increases until reaching a maximum. At the end of the re-vaporization $\left(\mathrm{T} \geq 750^{\circ} \mathrm{C}\right)$, we observe a strong absorption in the IBB-CEAS signal due to the significant presence of CsI aerosols (purple curve in Fig. 13): traces of iodine are emitted in the presence of large quantities of aerosols. The signal-to-noise ratio $(\mathrm{S} / \mathrm{N})$ becomes very poor due to increased light extinction by the presence of high aerosol concentrations.

Fig. 15 compares the spectra and the residuals of the fitting for two different furnace temperatures $\mathrm{T}=545^{\circ} \mathrm{C}$ (intermediate temperature) and $\mathrm{T}=750{ }^{\circ} \mathrm{C}$ (plateau temperature). As explained before (Fig. 13), the iodine signature is more significant at $\mathrm{T}=545{ }^{\circ} \mathrm{C}$ corresponding to a higher concentration of iodine released (about ten times greater than the amount of the iodine re-vaporized at $\mathrm{T}=750{ }^{\circ} \mathrm{C}$ ). Fig. 15 shows that the residual fit is clearly better at $545{ }^{\circ} \mathrm{C}$ where the amount of aerosols is negligible. 


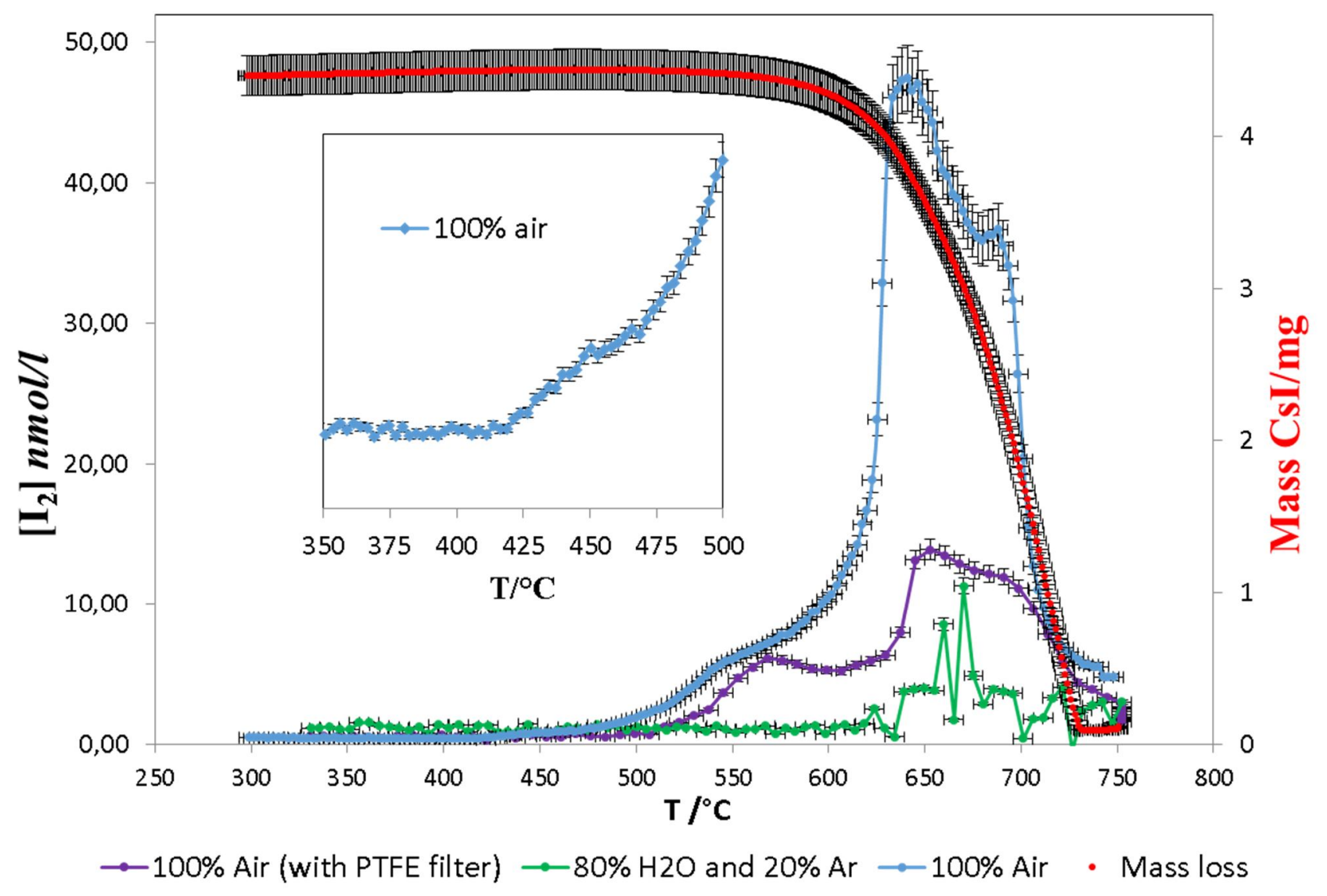

Figure. 14 The temperature profiles of the concentration of iodine re-vaporized detected via our IBB-CEAS absorption technique i) in blue under oxidizing atmosphere $100 \%$ air without filter ii) in violet under oxidizing atmosphere $100 \%$ air with PTFE filter and iii) in green under a steam atmosphere $\left.\left(80 \% \mathrm{H}_{2} \mathrm{O}\right)\right)$. Also shown in red is the mass loss of CsI previously deposited, measured by thermogravimetric analysis (TGA). In the figure zoom an enlargement of the temperature profile in the case of $100 \%$ air shows that the iodine release starts at a temperature $\sim 425{ }^{\circ} \mathrm{C}$. 

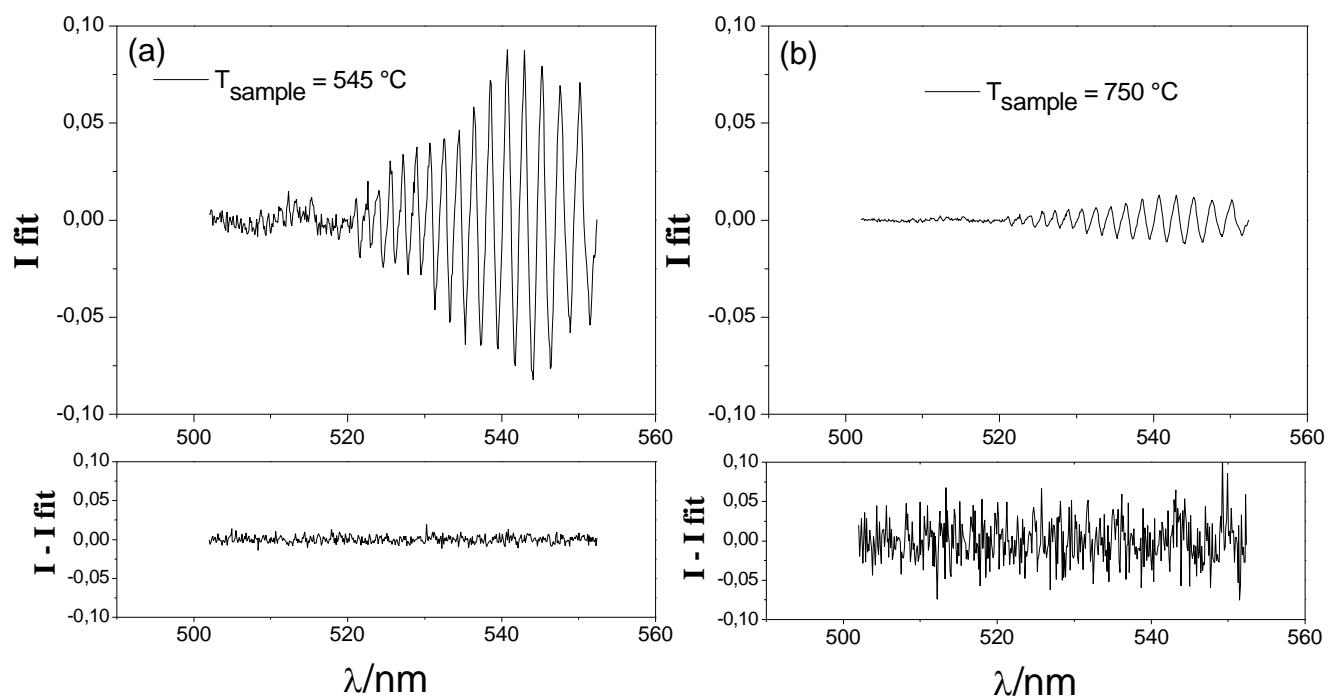

Figure. 15 Spectrum of iodine (the rapidly varying part after subtraction of the $25^{\text {th }}$-degree polynomial) released at a furnace temperature of $\sim 545^{\circ} \mathrm{C}$ is shown in the upper panel (a) for an $\mathrm{I}_{2}$ concentration of $\sim 4.2 \mathrm{nmol} / \mathrm{l}$. Below also displayed the residual fit between the sampling and the calibration $\times N_{\text {rel }}$ spectra. By comparison of the spectrum and the residual fit of iodine re-vaporized under the same conditions at $\sim 750{ }^{\circ} \mathrm{C}$ is plotted in (b) for an $\mathrm{I}_{2}$ concentration of $\sim 0.3 \mathrm{nmol} / \mathrm{l}$.

The different spectra of Fig. 13 are converted to concentrations thanks to calibration and DOAS method as explained in detail in section II.1.1 and led to the temperature profile displayed in blue curve in Fig. 14. Each iodine spectrum is cumulated for $30 \mathrm{~s}$.

The consistency of such experiments was checked with independent experiments performed by thermogravimetric analysis (SETSYS EVO TGA) allowing the monitoring of CsI mass loss with an accuracy of $\pm 1 \mu \mathrm{g}$.

The mass losses obtained by thermogravimetric experiments and the iodine release profiles are consistent. According to Fig. 14, the iodine detachment occurs at a temperature around $\sim 425$ $\pm 5^{\circ} \mathrm{C}$. The iodine release starts a little earlier than the mass loss.

TG measurements showed that more than $90 \%$ of the deposited caesium iodide can be revaporized in an air atmosphere.

To be close to conditions of some severe accident scenarios, experiments using steam atmosphere were conducted. TG experiments showed that re-vaporization of CsI starts almost at the same temperature, resulting in the re-vaporization of $\sim 100 \%$ of deposited sample ${ }^{(56)}$. One striking fact is the very low amount of gaseous iodine released in the presence of water vapour, as shown in green in Fig. 14. This aspect will be further studied in future experiments. 
Note that in case 2 of Fig. 14, the use of a filter at the furnace outlet upstream the optical cavity and before the dilution reduces the amount of gaseous iodine detected by $\sim 70 \%$ as shown in Fig. 14. This strong reduction of the $I_{2}$ signal may be due to iodine interaction with particles collected in the filter, assumed to be $\mathrm{CsOH}^{(57)}$ as shown by EDX observations (Fig. 12) which indicated the presence of Cs-containing particles. The aerosols collected on the filtres are potentially $\mathrm{CsOH}$ particles and on the basis of D. Obada et al. ${ }^{(56)} \mathrm{I}_{2}$ reacts with these aerosols to form CsI (which is shown by the EDX analyzes). This feature clearly justifies the use of IBBCEAS technique instead of filters.

From the experimental data it can be seen that under the conditions of severe accident scenarios the CsI will probably vaporize very rapidly in a steam atmosphere without molecular iodine detachment in the gaseous phase, while in presence of air -even in low amounts- $I_{2}$ is detected with a two-phase release kinetics.

The IBB-CEAS coupling to a reactor flow is expected to help in interpreting the above mentioned experimental evidence of vaporization and the forthcoming results under mixed air and steam conditions.

\section{Conclusion and outlook}

IBB-CEAS is a sensitive, simple, compact and robust device with a short response time and a large dynamic range which makes it ideal for portable setups. The instrument operates in the $\sim 490-555 \mathrm{~nm}$ spectral range and provides a high sensitivity analytical tool (minimum detectable absorption coefficient of $\sim 5 \times 10^{-8} \mathrm{~cm}^{-1}$ ). An excellent dynamic range was achieved thanks to high dilution capacities. The performances achieved are illustrated by high sensitivity recordings of the very weak absorption spectrum of water vapour in the wavelength region accessible by our LED. We were able to estimate a measured detection limit for iodine of the order of $1 \mathrm{ppb}$ for a cavity length of $\sim 50 \mathrm{~cm}$ and an acquisition time of $\sim 10 \mathrm{~s}$. We can improve the sensitivity of our IBB-CEAS device by increasing the acquisition time. These sensitivities compare well with current techniques used for the monitoring of $\mathrm{I}_{2}, \mathrm{IO}$ and $\mathrm{OIO}$ in the troposphere confirming, therefore, that IBB-CEAS is a potentially powerful tool in both atmospheric measurement campaigns and laboratory studies. On the other hand, the high levels of iodine detected in this work show that this precise method could be applied without any problems for the investigation of iodine emission in the nuclear field.

We have presented a first application of IBB-CEAS in nuclear field for the study of $\mathrm{I}_{2}$ in the presence of high concentrations of water vapour and aerosols. The study of the re-vaporization 
up to $750^{\circ} \mathrm{C}$ of $\mathrm{CsI}$ aerosols deposited on stainless steel coupons simulating the reactor coolant system surface state in the late phase of a severe accident was performed by coupling the IBBCEAS technique to an open flow reactor device. Re-vaporization of CsI was investigated in different atmosphere compositions (synthetic air and water vapour/argon). In presence of oxygen, $I_{2}$ is the main species detected at the outlet of the open flow reactor. However, in steam atmosphere, the main species transported in the line of the open flow reactor is CsI while $\mathrm{I}_{2}$ was not detected or present only in trace amount. This example of application shows also that IBBCEAS works well with these water vapour and aerosol concentrations when the presence of a filter strongly disturbs the acquisition.

This IBB-CEAS coupling to a flow reactor will enable an improved understanding of the important chemical interactions in the reactor coolant system and thus permit a more accurate simulation of the primary circuit chemistry in a severe nuclear accident, and hence help reducing the uncertainties in estimating the source term to the environment.

We look to improve the retrieval approach in the future to be able to account for several absorbing species in the same wavelength region $\left(\underline{\mathrm{I}}_{2}, \mathrm{H}_{2} \mathrm{O}\right)$ by performing a multilinear adjustment of the fast portion of the absorption spectrum. The absorber amounts of $\mathrm{I}_{2} \underline{\text { and } \mathrm{H}_{2}} \underline{\mathrm{O}}$ can be retrieved by fitting the differential structure in the IBB-CEAS spectra with the absorption cross-sections of $\mathrm{I}_{2}$ reported by Saiz-Lopez et al. and the absorption cross-sections of $\mathrm{H}_{2} \underline{O}$ measured by Coheur and Fally, convoluted to the instrument function of the spectrograph. For

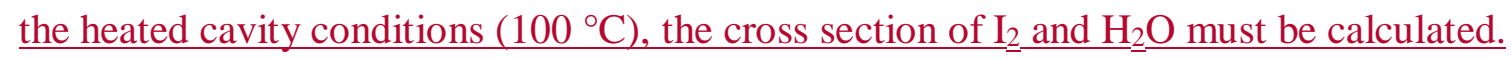

The forthcoming objective is to implement and operate in situ the IBB-CEAS device at the exit of the Reactor Coolant System.

Theoretical investigation as well as experimental tests are planned that will serve to improve the modelling of containment phenomenology in the ASTEC simulation code (Accident Source Term Evaluation Code) currently developed in IRSN for computing severe accidents.

\section{Acknowledgements}

This work was supported by the French State under the program "Investissements d'Avenir" MiRE managed by the ANR under Grant Agreement No. ANR-11-RSNR-0013-01. The authors would like to acknowledge Yves Benilan (University of UPEC, France) for useful discussions and comments in simulation of water vapour spectra, IRSN operators Calogero Tornabene, Vincent Cozar, and Guillaume Basso for their help and technical assistance. Sebastien Batut 
Ingénieur d'étude CNRS is acknowledged for assistance in the development of LabVIEW programmes.

\section{References}

(1) D. Jacquemain, Institut de Radioprotection et de Sûreté Nucléaire IRSN, Nuclear Power Reactor Core Melt Accidents, (Science and Technology Series, France 2015).

${ }^{(2)}$ O. Masson, A. Baeza, J. Bieringer, K. Brudecki, S. Bucci, M. Cappai, F. P. Carvalho, O. Connan, C. Cosma, A. Dalheimer, D. Didier, G. Depuydt, L. E. De Geer, A. De. Vismes, L. Gini, F. Groppi, K. Gudnason, R. Gurriaran, D. Hainz, Ó. Halldórsson, D. Hammond, O. Hanley, K. Holeý, Zs. Homoki, A. Ioannidou, K. Isajenko, M. Jankovic, C. Katzlberger, M. Kettunen, R. Kierepko, R. Kontro, P. J. M. Kwakman, M. Lecomte, L. Leon Vintro, A. -P. Leppänen, B. Lind, G. Lujaniene, P. Mc Ginnity, C. Mc Mahon, H. Malá, S. Manenti, M. Manolopoulou, A. Mattila, A. Mauring, J. W. Mietelski, B. Møller, S. P. Nielson, J. Nikolic, R. M. W. Overwater, S. E. Pálsson, C. Papastefanou, I. Penev, M. K. Pham, P. P. Povinec, H. Ramebäck, M. C. Reis, W. Ringer, A. Rodriguez, P. Rulík, P. R. J. Saey, V. Samsonov, C. Schlosser, G. Sgorbati, B. V. Silobritiene, C. Söderström, R. Sogni, L. Solier, M. Sonck, G. Steinhauser, T. Steinkopff, P. Steinmann, S. Stoulos, I. Sýkora, D. Todorovic, N. Tooloutalaie, L. Tositti, J. Tschiersch, A. Ugron, E. Vagena, A. Vargas, H. Wershofen, O. Zhukova, Tracking of Airborne Radionuclides from the Damaged Fukushima Dai-Ichi Nuclear Reactors by European Networks, Environ. Sci. Technol. 45 (2011) 7670-7677.

(3) J. Couturier, M. Schwarz, Institut de Radioprotection et de Sûreté Nucléaire IRSN, État des recherches dans le domaine de la sureté des réacteurs à eau sous pression, (collection sciences et techniques, France 2017.

(4) L. Cantrel, L. Bosland, C. Mun, T. Albiol, C. Monsanglant-Louvet, B. Azambre, C. Volkringer, IRSN R\&D actions on FP behaviour for RCS, containment and FCVS in severe accident conditions, Proceedings of 24th International Conference on Nuclear Engineering, June 26-30, 2016 - Charlotte (United States). 
(5) K. Moriyama, S. Tashiro, N. Chiba, F. Hirayama, Y. Maruyama, H. Nakamura, A. Watanabe, Experiments on the Release of Gaseous Iodine from Gamma-Irradiated Aqueous CsI Solution and Influence of Oxygen and Methyl Isobutyl Ketone (MIBK), J. Nucl. Sci. Technol. 47 (2010) 229-237.

${ }^{(6)}$ A.-C. Grégoire, J. Kalilainen, F. Cousin, H. Mutelle, L. Cantrel, A. Auvinen, T. Haste, S. Sobanska, Studies on the role of molybdenum on iodine transport in the RCS in nuclear severe accident conditions, Ann. Nucl. Energy, 78 (2015) 117-129.

(7) O. Johansson, H. Mutelle, A. E. Parker, S. Batut, P. Demaux, C. Schoemaecker, C. Fittschen, Quantitative IBB-CEAS measurements of $\mathrm{I}_{2}$ in the presence of aerosols, Appl. Phys. B 114 (2014) 421-432.

${ }^{(8)}$ T. Hoffmann, R. J. Huang, M. Kalberer, Atmospheric Analytical Chemistry, Anal. Chem. 83 (2011) 4649-4664.

${ }^{(9)}$ A. Saiz-Lopez, J. A. Shillito, H. Coe, J. M. C. Plane, Measurements and modelling of $\mathrm{I}_{2}$, IO, $\mathrm{OIO}, \mathrm{BrO}$ and $\mathrm{NO}_{3}$ in the mid-latitude marine boundary layer, Atmos. Chem. Phys. 6 (2006) 1513-1528.

${ }^{(10)}$ R. J. Leigh, S. M. Ball, J. Whitehead, C. Leblanc, A. J. L. Shillings, A. S. Mahajan, H. Oetjen, J. D. Lee, C. E. Jones, J. R. Dorsey, M. Gallagher, R. L. Jones, J. M. C. Plane, P. Potin, G. McFiggans, Measurements and modelling of molecular iodine emissions, transport and photodestruction in the coastal region around Roscoff, Atmos. Chem. Phys. 10 (2010) 1182311838.

${ }^{(11)}$ R.-J. Huang, K. Seitz, J. Buxmann, D. Pöhler, K. E. Hornsby, L. J. Carpenter, U. Platt, T. Hoffmann, In situ measurements of molecular iodine in the marine boundary layer: the link to macroalgae and the implications for $\mathrm{O}_{3}$, IO, OIO and $\mathrm{NO}_{x}$, Atmos. Chem. Phys. 10 (2010) 4823-4833.

(12) J. Lampel, D. Pöhler, O. L. Polyansky, A. A. Kyuberis, N. F. Zobov, J. Tennyson, L. Lodi, U. Frie $\beta$, Y. Wang, S. Beirle, U. Platt, T. Wagner, Detection of water vapour absorption around $363 \mathrm{~nm}$ in measured atmospheric absorption spectra and its effect on DOAS evaluations, Atmos. Chem. Phys. 17 (2017) 1271-1295.

${ }^{(13)}$ Q. Lin, X. Liu, Z. Jin, Q. Zheng, Buffer gas effect on the detection of iodine by laser induced fluorescence, J. Radioanal. Nucl. Chem. Lett. 212 (1996) 313-320. 
(14) S. V. Kireev, S. L. Shnyrev, Laser-induced fluorescence method of molecular iodine detection in the atmosphere in real time using copper-vapor laser at the wavelength of 510.6 nm, Laser. Phys. Lett. 14 (2017) 065701 (5pp).

(15) J. C. Gómez Martín, J. Blahins, U. Gross, T. Ingham, A. Goddard, A. S. Mahajan, A. Ubelis, A. Saiz-Lopez, In situ detection of atomic and molecular iodine using Resonance and OffResonance Fluorescence by Lamp Excitation: ROFLEX, Atmos. Meas. Tech. 4 (2011) 29-45. (16) R.J. Chance, M. Shaw, L. Telgmann, M. Baxter, L. J. Carpenter, A comparison of spectrophotometric and denuder based approaches for the determination of gaseous molecular iodine, Atmos. Meas. Tech. 3 (2010) 177-185.

(17), M. Kundel, U. R. Thorenz, J. H. Petersen, R.-J. Huang, N. H. Bings, T. Hoffmann, Application of mass spectrometric techniques for the trace analysis of short-lived iodinecontaining volatiles emitted by seaweed, Anal. Bioanal. Chem 402 (2012) 3345-3357.

${ }^{(18)}$ U. R. Thorenz, L. J. Carpenter, R.-J. Huang, M. Kundel, J. Bosle, T. Hoffmann, Emission of iodine-containing volatiles by selected microalgae species, Atmos. Chem. Phys. 14 (2014) 13327-13335.

${ }^{(19)}$ M. J. Lawler, A. S. Mahajan, A. Saiz-Lopez, E. S. Saltzman, Observations of $I_{2}$ at a remote marine site, Atmos. Chem. Phys. 14 (2014) 2669-2678.

${ }^{(20)}$ M. Bitter, S. M. Ball, I. M. Povey, R. L. Jones, A broadband cavity ringdown spectrometer for in-situ measurements of atmospheric trace gases, Atmos. Chem. Phys. 5 (2005) 2547-2560.

(21) Y. Sakamoto, A. Yabushita, M. Kawasaki, S. Enami, Direct Emission of $\mathrm{I}_{2}$ Molecule and IO Radical from the Heterogeneous Reactions of Gaseous Ozone with Aqueous Potassium Iodide Solution, J. Phys. Chem. A, 113 (2009) 7707-7713.

${ }^{(22)}$ S. Vaughan, T. Gherman, A. A. Ruth, J. Orphal, Incoherent broad-band cavity-enhanced absorption spectroscopy of the marine boundary layer species $\mathrm{I}_{2}, \mathrm{IO}$ and OIO, Phys. Chem. Chem. Phys. 10 (2008) 4471-4477.

${ }^{(23)}$ K. C. Cossel, E. M. Waxman, I. A. Finneran, G. A. Blake, J. Ye, N. R. Newbury, Gas-phase broadband spectroscopy using active sources: progress, status, and applications, J. Opt. Soc. Am. B. 34 (2017) 104-129. 
${ }^{(24)}$ C. Bahrini, Y. Bénilan, A. Jolly, B. Lebert, X. Landsheere, M.-C. Gazeau, Pulsed cavity ring-down spectrometer at $3 \mu \mathrm{m}$ based on difference frequency generation for high-sensitivity $\mathrm{CH}_{4}$ detection, Appl. Phys. B 121 (2015) 533-539.

(25) S. Dixneuf, A. A. Ruth, S. Vaughan, R. M. Varma, J. Orphal, The time dependence of molecular iodine emission from Laminaria digitata, Atmos. Chem. Phys. 9 (2009) 823-829.

(26) U. Nitschke, A. A. Ruth, S. Dixneuf, D. B. Stengel, Molecular iodine emission rates and photosynthetic performance of different thallus parts of Laminaria digitata (Phaeophyceae) during emersion, Planta. 233 (2011) 737-748.

${ }^{(27)}$ P. S. Johnston, K. K. Lehmann, Cavity enhanced absorption spectroscopy using a broadband prism cavity and a supercontinuum source, Opt. Express. 16 (2008) 15013-15023.

(28) A. Aalto, G. Genty, T. Laurila, J. Toivonen, Incoherent broadband cavity enhanced absorption spectroscopy using supercontinuum and superluminescent diode sources, Opt. Express. 23 (2015) 25225-25234.

(29) S. M. Ball, J. M. Langridge, R. L. Jones, Broadband cavity enhanced absorption spectroscopy using light emitting diodes, Chem. Phys. Lett. 398 (2004) 68-74.

${ }^{\left({ }^{30)}\right.}$ H. Yi, T. Wu, G. Wang, W. Zhao, E. Fertein, C. Cour, X. Gao, W. Zhang, W. Chen, Sensing atmospheric reactive species using light emitting diode by incoherent broadband cavity enhanced absorption spectroscopy, Opt. Express. 24 (2016) 781-790.

(31) M. Triki, P. Cermak, G. Méjean, D. Romanini, Cavity-enhanced absorption spectroscopy with a red LED source for $\mathrm{NO}_{\mathrm{x}}$ trace analysis, Appl. Phys. B. 91 (2008) 195-201.

${ }^{(32)}$ R. A. Washenfelder, A. O. Langford, H. Fuchs, S. S. Brown, Measurement of glyoxal using an incoherent broadband cavity enhanced absorption spectrometer, Atmos. Chem. Phys. 8 (2008) 7779-7793.

${ }^{(33)}$ R. A. Washenfelder, A. R. Attwood, J. M. Flores, K. J. Zarzana, Y. Rudich, S. S. Brown, Broadband cavity-enhanced absorption spectroscopy in the ultraviolet spectral region for measurements of nitrogen dioxide and formaldehyde, Atmos. Meas. Tech. 9 (2016) 41-52.

(34) S. E. Fiedler, A. Hese, A. A. Ruth, Incoherent broad-band cavity-enhanced absorption spectroscopy, Chem. Phys. Lett. 371 (2003) 284-294.

${ }^{(35)}$ A. L. Gomez, E. P. Rosen, Fast response cavity enhanced ozone monitor, Atmos. Meas. Tech 6 (2013) 487-494. 
(36) J. Chen, D. S. Venables, A broadband optical cavity spectrometer for measuring weak nearultraviolet absorption spectra of gases, Atmos. Meas. Tech. 4 (2011) 425-436.

${ }^{(37)}$ M. Dong, W. Zhao, M. Huang, W. Chen, C. Hu, X. Gu, S. Pei, W. Huang, W. Zhang, Nearultraviolet Incoherent Broadband Cavity Enhanced Absorption Spectroscopy for OClO and $\mathrm{CH}_{2} \mathrm{O}$ in Cl-initiated Photooxidation Experiment, Chin. J. Chem. Phys. 26 (2013) 133-139.

(38) R. Thalman, R. Volkamer, Inherent calibration of a blue LED-CE-DOAS instrument to measure iodine oxide, glyoxal, methyl glyoxal, nitrogen dioxide, water vapour and aerosol extinction in open cavity mode, Atmos. Meas. Tech. 3 (2010) 1797-1814.

${ }^{(39)}$ R. Thalman, M. T. Baeza-Romero, S. M. Ball, E. Borrás, M. J. S. Daniels, I. C. A. Goodall, S. B. Henry, T. Karl, F. N. Keutsch, S. Kim, J. Mak, P. S. Monks, A. Muñoz, J. Orlando, S. Peppe, A. R. Rickard, M. Ródenas, P. Sánchez, R. Seco, L. Su, G. Tyndall, M. Vázquez, T. Vera, E. Waxman, R. Volkamer, Instrument intercomparison of glyoxal, methyl glyoxal and $\mathrm{NO}_{2}$ under simulated atmospheric conditions, Atmos. Meas. Tech. 8 (2015) 1835-1862.

${ }^{(40)}$ J. M. Langridge, T. Laurila, R. S. Watt, R. L. Jones, C. F. Kaminski, J. Hult, Cavity enhanced absorption spectroscopy of multiple trace gas species using a supercontinuum radiation source, Opt. Express. 16 (2008) 10178-10188.

${ }^{(41)}$ S. Coburn, I. Ortega, R. Thalman, B. Blomquist, C. W. Fairall, R. Volkamer, Measurements of diurnal variations and eddy covariance (EC) fluxes of glyoxal in the tropical marine boundary layer: description of the Fast LED-CE-DOAS instrument, Atmos. Meas. Tech. 7 (2014) 35793595 .

(42) H. Wang, J. Chen, K. Lu, Development of a portable cavity-enhanced absorption spectrometer for the measurement of ambient $\mathrm{NO}_{3}$ and $\mathrm{N}_{2} \mathrm{O}_{5}$ : experimental setup, lab characterizations, and field applications in a polluted urban environment, Atmos. Meas. Tech. 10 (2017) 1465-1479.

(43) J. Stutz, U. Platt, Numerical analysis and estimation of the statistical error of differential optical absorption spectroscopy measurements with least-squares methods, Appl.Optics. 35 (1996) 6041-6053.

${ }^{(44)}$ U. Platt, J. Stutz, Differential Optical Absorption Spectroscopy (Springer, Berlin, 2008).

${ }^{(45)}$ U. Platt, J. Meinen, D. Pöhler,T. Leisner: Broadband Cavity Enhanced Differential Optical Absorption Spectroscopy (CE-DOAS) - applicability and corrections, Atmos. Meas. Tech., 2 (2009) 713-723. 
(46) J. Meinen, J. Thieser, U. Platt, T. Leisner, Technical Note: Using a high finesse optical resonator to provide a long light path for differential optical absorption spectroscopy: CEDOAS, Atmos. Chem. Phys. 10 (2010) 3901-3914.

${ }^{(47)}$ I. Sanemasa, T. Kobayashi, C. Y. Piao, T. Deguchi, Equilibrium Solubilities of Iodine Vapor in Water, Bull. Chem. Soc. Jpn. 57 (1984) 1352-1357.

${ }^{(48)}$ L. Ntziachristos, S. Amanatidis, Z. Samaras, K. Janka, J. Tikkanen, Application of the Pegasor Particle Sensor for Measurement of Mass and Particle Number Emissions, SAE Int. J. Fuels Lubr. 6(2) (2013). Doi: 10.4271/2013-01-1561.

${ }^{(49)}$ A. Saiz-Lopez, R. W. Saunders, D. M. Joseph, S. H. Ashworth, J. M. C. Plane, Absolute absorption cross-section and photolysis rate of $\mathrm{I}_{2}$, Atmos. Chem. Phys. 4 (2004) 1443-1450.

${ }^{(50)}$ P.-F. Coheur, S. Fally, M. Carleer, C. Clerbaux, R. Colin, A. Jenouvrier, M.-F. Mérienne,

C. Hermans, A. C. Vandaele, New water vapor line parameters in the $26000-13000 \mathrm{~cm}^{-1}$ region, J. Quant. Spectrosc. Radiat. Transfer. 74 (2002) 493-510.

${ }^{(51)}$ S. Fally, P.-F. Coheur, M. Carleer, C. Clerbaux, R. Colin, A. Jenouvrier, M.-F. Mérienne, C. Hermans, A. C. Vandaele, Water vapor line broadening and shifting by air in the 26000$13000 \mathrm{~cm}^{-1}$ region, J. Quant. Spectrosc. Radiat. Transfer. 82 (2003) 119-131.

${ }^{(52)}$ S. Suzuki, H. Wagata, M. Komatsus, T. Minegishi, K. Domen, S. Oishi, K. Teshima, A novel flux coating method for the fabrication of layers of visible-light-responsive $\mathrm{Ta}_{3} \mathrm{~N}_{5}$ crystals on tantalum substrates, J. Mater. Chem. A. 3 (2015) 13946-13952.

${ }^{(53)}$ H. Geng, S. Kang, H.-J. Jung, M. Choël, H. Kim, C.-Un. Ro, Characterization of individual submicrometer aerosol particles collected in Incheon, Korea, by quantitative transmission electron microscopy energy-dispersive X-ray spectrometry, J. Geophys. Res. 115 (2010) 1-15. ${ }^{(54)}$ K. Knebel, P. D. W. Bottomley, V. V. Rondinella, A. Auvinen, J. Jokiniemi, An experimental device to study the revaporisation behaviour of fission product deposits under severe accident conditions, Prog. Nucl. Energy. 72 (2014) 77-82.

${ }^{(55)}$ P. D. W. Bottomley, K. Knebel, S. V. Winckel, T. Haste, S. M. O. Souvi, A. Auvinen, J. Kalilainen, T. Kärkelä, Revaporisation of fission product deposits in the primary circuit and its impact on accident source term, Ann. Nucl. Energy. 74 (2014) 208-223.

(56) D. Obada, L. Gasnot, A.-S. Mamede, A.-C. Grégoire, assessment of medium-term radioactive releases in case of a severe nuclear accident on a Pressurized Water Reactor: experimental study of fission products re-vaporization from deposits (Cs,I), Proceedings of ICAPP 2017, April 24-28, 2017 - Fukui and Kyoto (Japan) nº 17328. 
(57) M. Gouello, H. Mutelle, F. Cousin, S. Sobanska, E. Blanquet, Analysis of the iodine gas phase produced by interaction of CsI and $\mathrm{MoO}_{3}$ vapours in flowing steam, Nucl. Eng. Des. 263 (2013) 462-472.

\section{Figure captions}

Figure. 1 Diagram of the gas lines connected to the optical cell of the IBB-CEAS device. Bypass lines are shown in Fig. 1 by purple dotted arrows.

Figure. 2 (a) The intensity of transmitted light recorded with only the carrier gas inside the cavity $I_{0}$ (blue curve) and $I_{\text {sample }}$ the intensity of transmitted light recorded with sample gas inside the cavity (red curve). (b) The absorption cross-section from Saiz-Lopez et al. ${ }^{(49)}$. (c) The function $\frac{1-R(\lambda)}{d}$ deduced from equation (1) using $\mathrm{I}_{2}$ species and $\sigma$ from Saiz-Lopez et al. (49). (d) The reflectivity $R$ approximated by omitting the shortening of the value of $\mathrm{d}$ by the mirror protection flow.

Figure. 3 (a) Upper graph: in blue water vapour line intensities (integrated cross-section) obtained by combining a high-resolution Fourier transform spectrometer with a long-path absorption cell by Coheur and Fally ${ }^{(50,51)}$. Lower graph: $\mathrm{H}_{2} \mathrm{O}$ IBB-CEAS spectrum (this work) in black line, in red is displayed the calculated spectrum using a convolution of the highresolution Fourier transform spectrometer water vapour line intensities ${ }^{(50,51)}$ with square function $\mathrm{FWHM}=1 \mathrm{~nm}$.

http://satellite.mpic.de/spectral_atlas

Figure. 4 Blue line: High frequency part of the pure iodine spectrum recorded by IBB-CEAS technique for an iodine concentration of $\sim 18.3 \mathrm{nmol} / \mathrm{l}$ after subtraction of polynomial fit. Red line: the IBB-CEAS spectrum of a mixture of iodine and $35 \%$ water vapour by volume in the mixing line. The $\mathrm{H}_{2} \mathrm{O}$ absorption peak around $505 \mathrm{~nm}$ is clearly visible (for $\mathrm{H}_{2} \mathrm{O}$, there is only "positive" absorption above the polynomial fit), the $\mathrm{H}_{2} \mathrm{O}$ peak at $545 \mathrm{~nm}$ is hidden in $\mathrm{I}_{2}$-structure and is too weak to be visible.

Figure. 5 Water vapour effect on the iodine concentration. Upper panel: blue marks: expected density of iodine (without water vapour), red marks: density of iodine measured in the presence of water vapour obtained by fitting in the range $490-550 \mathrm{~nm}$. Lower panel: the relative deviation from the expected iodine density.

Figure. 6 Atomized $\mathrm{NaCl}$ aerosols measured using NanoScan SMPS. Effect of the solution concentration on the salt particles distribution generated by the Atomizer.

Figure. 7 Effect of the nature of the solute on the size distribution of generated aerosols. 
Figure. 8 The coefficient $\frac{I_{0-} B_{g}}{I-B_{g}}-1$, describing light extinction due to aerosols inside the cell for different salt $(\mathrm{NaCl})$ concentrations.

Figure. 9 Effect of the nature of the solution on the light extinction coefficient $\left(\frac{I_{0-} B_{g}}{I-B_{g}}-1\right)$ for the same mass density of $0.3 \mathrm{~g} / \mathrm{l}$.

Figure. 10 Effect of the $\left(\mathrm{NaCl}, \mathrm{KCl}\right.$ and $\left.\mathrm{Na}_{2} \mathrm{CO}_{3}\right)$ aerosols on the $\mathrm{I}_{2}$ concentrations: Measured $\mathrm{I}_{2}$ concentrations versus different aerosol fractional extinction.

Figure. 11 RIGolo device coupled with on-line optical gaseous molecular iodine monitoring by IBB-CEAS. MFC mass flow controller, Ar argon, $L E D$ light-emitting diode, $L 1$ lens, $L 2$ lens, F1 Thorlabs FGL495 optical filter, $F 2$ Thorlabs FES0550 optical filter, $M F$ mirror flow, $G I$ gas inlet, $G O$ gas outlet, $P T 1, P T 2$ pressure meter and thermocouple, $C F$ charcoal filter, $C O$ critical orifice, $P$ pressure meter, $V P$ vacuum pump, Spec spectrometer, Cam camera.

Figure. 12 Characterization of individual submicrometre aerosol particles collected in a PTFE filter, by the SEM-EDX method. The upper image describes the morphology of the Cs-I particles, the lower is the EDX Spectrum.

Figure. 13 Intensity of the transmitted light recorded with iodine re-vaporized for different temperature of the furnace. For calibration measurements, a known external source of molecular iodine was used. The calibration concentration was $\left[\mathrm{I}_{2}\right] \approx 5 \mathrm{nmol} / \mathrm{l}$ corresponding to a furnace temperature about $\sim 550{ }^{\circ} \mathrm{C}$. The calibration in the middle of the concentration range of iodine is plotted in black dotted line.

Figure. 14 The temperature profiles of the concentration of iodine re-vaporized detected via our IBB-CEAS absorption technique i) in blue under oxidizing atmosphere $100 \%$ air without filter ii) in violet under oxidizing atmosphere $100 \%$ air with PTFE filter and iii) in green under a steam atmosphere $\left.\left(80 \% \mathrm{H}_{2} \mathrm{O}\right)\right)$. Also shown in red is the mass loss of CsI previously deposited, measured by thermogravimetric analysis (TGA). In the figure zoom an enlargement of the temperature profile in the case of $100 \%$ air shows that the iodine release starts at a temperature $\sim 425^{\circ} \mathrm{C}$.

Figure. 15 Spectrum of iodine (the rapidly varying part after subtraction of the $25^{\text {th }}$-degree polynomial) released at a furnace temperature of $\sim 545^{\circ} \mathrm{C}$ is shown in the upper panel (a) for an $\mathrm{I}_{2}$ concentration of $\sim 4.2 \mathrm{nmol} / \mathrm{l}$. Below also displayed the residual fit between the sampling and the calibration $\times N_{\text {rel }}$ spectra. By comparison of the spectrum and the residual fit of iodine re-vaporized under the same conditions at $\sim 750{ }^{\circ} \mathrm{C}$ is plotted in (b) for an $\mathrm{I}_{2}$ concentration of $\sim 0.3 \mathrm{nmol} / \mathrm{l}$. 